\title{
An inverse modeling approach to estimating phytoplankton pigment concentrations from phytoplankton absorption spectra
}

\author{
John R. Moisan, ${ }^{1}$ Tiffany A. H. Moisan, ${ }^{1}$ and Matthew A. Linkswiler ${ }^{2}$ \\ Received 3 November 2010; revised 8 June 2011; accepted 16 June 2011; published 17 September 2011.
}

[1] Phytoplankton absorption spectra and High-Performance Liquid Chromatography

(HPLC) pigment observations from the Eastern U.S. and global observations from

NASA's SeaBASS archive are used in a linear inverse calculation to extract pigmentspecific absorption spectra. Using these pigment-specific absorption spectra to reconstruct the phytoplankton absorption spectra results in high correlations at all visible wavelengths ( $\mathrm{r}^{2}$ from 0.83 to 0.98 ), and linear regressions (slopes ranging from 0.8 to 1.1 ). Higher correlations $\left(\mathrm{r}^{2}\right.$ from 0.75 to 1.00$)$ are obtained in the visible portion of the spectra when the total phytoplankton absorption spectra are 'unpackaged' by multiplying the entire spectra by a factor that sets the total absorption at $675 \mathrm{~nm}$ to that expected from absorption spectra reconstruction using measured pigment concentrations and laboratory-derived pigment-specific absorption spectra. The derived pigment-specific absorption spectra were further used with the total phytoplankton absorption spectra in a second linear inverse calculation to estimate the various phytoplankton HPLC pigments. A comparison between the estimated and measured pigment concentrations for the 18 pigment fields showed good correlations $\left(\mathrm{r}^{2}>0.5\right)$ for 7 pigments and very good correlations $\left(\mathrm{r}^{2}>0.7\right)$ for chlorophyll $a$ and fucoxanthin. Higher correlations result when the analysis is carried out at more local geographic scales. The ability to estimate phytoplankton pigments using pigment-specific absorption spectra is critical for using hyperspectral inverse models to retrieve phytoplankton pigment concentrations and other Inherent Optical Properties (IOPs) from passive remote sensing observations.

Citation: Moisan, J. R., T. A. H. Moisan, and M. A. Linkswiler (2011), An inverse modeling approach to estimating phytoplankton pigment concentrations from phytoplankton absorption spectra, J. Geophys. Res., 116, C09018, doi:10.1029/2010JC006786.

\section{Introduction}

[2] The light absorption properties of marine phytoplankton influence the manner in which solar energy radiates through the ocean and control the level of energy made available to phytoplankton for primary production. Phytoplankton can absorb light across the visible and into the UV portion of the light spectrum. Knowledge on the shape of phytoplankton absorption spectra is a requirement in present inverse models that estimate phytoplankton chlorophyll concentrations [IOCCG, 2006] and for input into bio-optical models that predict carbon fixation rates for the global ocean [Behrenfeld and Falkowski, 1997; Carr et al., 2006]. The shape and the magnitude of the phytoplankton absorption spectra is controlled primarily by the concentration of various photosynthetic and photoprotective pigments and by the level of pigment package effect within the cells [Stuart et al., 1998;

${ }^{1}$ Hydrospheric and Biospheric Sciences Laboratory, Wallops Flight Facility, NASA Goddard Space Flight Center, Wallops Island, Virginia, USA.

${ }^{2}$ URS Corporation, Wallops Flight Facility, NASA Goddard Space Flight Center, Wallops Island, Virginia, USA.

This paper is not subject to U.S. copyright. Published in 2011 by the American Geophysical Union.
Lohrenz et al., 2003], though the specific influence of these two processes varies with depth, phytoplankton species composition, cell size and physiology.

[3] Earlier attempts at reconstructing phytoplankton in vivo absorption spectra from pigment concentrations used in vitro pigment-specific absorption measurements of pure pigment standards 'shifted' spectrally to match observed shifts in the in vivo absorption maxima positions from pigment protein complexes within the cell [Bidigare et al., 1990]. This technique assumes that the reconstructed absorption spectra are a linear combination of the pigmentspecific absorption spectra from individual "unpackaged" pigments, such that the in vivo, "unpackaged" phytoplankton absorption spectra

$$
a_{p h}^{\prime}(\lambda)=\sum_{i=1}^{m} C_{i} a_{i}^{*}(\lambda),
$$

where $a_{i}^{*}(\lambda)$ is the individual weight-specific 'shifted' pigment absorption spectra derived from absorption spectra of individual pigments within a known solvent and $C_{i}$ is the concentration for the ith pigment. The terms 'weightspecific' and 'pigment-specific' absorption $\left[\mathrm{m}^{-2} \mathrm{mg}^{-1}\right]$ are used interchangeably in the scientific literature and hold the 


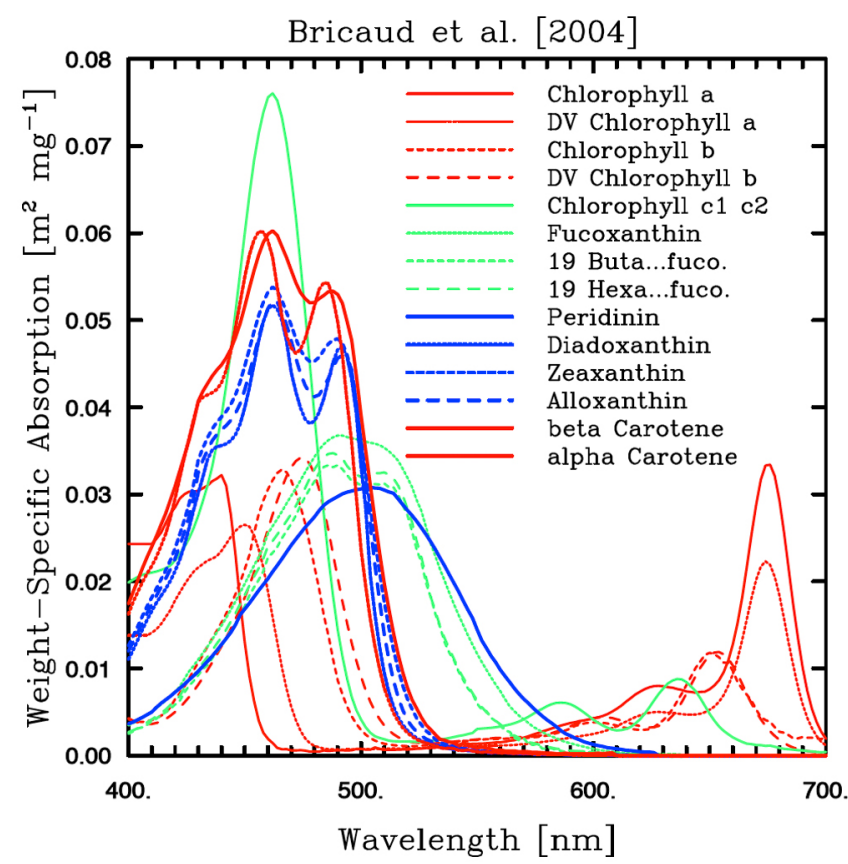

Figure 1. Weight-specific (or pigment-specific) in vitro absorption spectra of various pigments, $a_{i}^{*}(\lambda)$, derived from measuring the absorption spectra of individual pigments in solvent and shifting the maxima of the spectra according to Bidigare et al. [1990]. Data obtained courtesy of Annick Bricaud [see Bricaud et al., 2004]. Note that only 14 of the total 18 pigments encountered in this study have pigmentspecific relationships available from laboratory studies.

same definition of absolute absorption $\left[\mathrm{m}^{-1}\right]$ per concentration of a given pigment $\left[\mathrm{mg} \mathrm{m}^{-3}\right]$.

[4] Nelson et al. [1993], using a similar combination of absorption spectra and HPLC pigment measurements, noted that when pigment package effects were small the Bidigare et al. [1990] reconstruction method compared well to the measured absorption and that underestimates from the reconstruction method was likely due to absorption from phycobiliproteins or other pigments not measured in traditional HPLC analysis.

[5] In addition to the indirect reconstruction method (equation (1)), Hoepffner and Sathyendranath [1991] developed a technique that fitted the phytoplankton absorption spectra to combinations of Gaussian curves/ spectra such that the reconstruction of the in vivo phytoplankton absorption spectra

$$
a_{p h}^{\prime}(\lambda)=\sum_{i=1}^{L} c_{i} a_{\max , i}^{*} \exp \left[-\frac{\left(\lambda-\lambda_{i}\right)^{2}}{2 \sigma_{i}^{2}}\right],
$$

where $L$ denotes the number of total Gaussian curves to be summed over, $c_{i}$ is the concentration of the pigment associated with the individual Gaussian curve, $a_{\max , i}^{*}$ is the pigment-specific maximum absorption level associated with the center of the Gaussian curve located at the $\lambda_{i}$ wavelength, and $\sigma_{i}$ denotes the half width of the Gaussian curve. Analysis of the results from fitting 11 such Gaussian curves to a variety of phytoplankton culture absorption spectra from
9 species within 3 major algal groups (3 Bacillariophyta, 4 Chlorophyceae, and 2 Prymnesiophyceae) showed that Gaussian curve summations reconstruct the absorption spectra very well. However, attempts to model the variability in the various Gaussian curve parameters as a linear function of specific pigment concentrations showed mixed results, with coefficient's of determination, $r^{2}$, ranging from 0.33 to 0.99. Lutz et al. [1996] demonstrated that these Gaussian reconstructions of absorption spectra are improved if the ocean regions are partitioned according to their absorption characteristics. Using this technique, analysis of Arabian Sea and Vancouver Island seawater samples by Stuart et al. [1998] showed that $29-42 \%$ of the variability in absorption at $440 \mathrm{~nm}$ was due to changes in pigment composition and that $58-71 \%$ of the variability was due to pigment package effects. In a similar study using seawater samples from the coasts of North Carolina and Florida, Lohrenz et al. [2003] also noted that pigment package effects accounted for up to $62 \%$ of the variability in the absorption spectra maximum amplitude bands $\left(a_{\max , i}^{*}\right)$ and that variations in pigment composition only accounted for $10-28 \%$ of variations.

[6] Further attempts at refining this method [Evans and Cornford, 2003] have expanded the linear fit approach for modeling the pigment-specific maximum absorption such that the reconstructed in vivo phytoplankton absorption spectra

$$
a_{p h}^{\prime}(\lambda)=\sum_{i=1}^{m} c_{i} \sum_{j=1}^{L} a_{\max , i, j}^{*} \exp \left[-\frac{\left(\lambda-\lambda_{i}\right)^{2}}{2 \sigma_{i}^{2}}\right],
$$

such that a suite of $L$ Gaussian curves (each with a unique maximum absorption $a_{\max , i, j}^{*}$, half width $\sigma_{i, j}$ and central wave band $\lambda_{i, j}$ ) are linked to $\mathrm{n}$ pigments. The utility of this approach is that the resulting equation set can be used to compute pigment-specific absorption spectra similar to those developed initially by Bidigare et al. [1990]. However, implementation of this method has proved more challenging, likely due to correlations between pigment package effects and concentrations (D. Cornford, personal communication, 2010). In these latter two methods, the derived pigment-specific absorption spectra are influenced by the level of pigment package effects that occurs within various samples. Also, the numerical retrievals are based upon individually solving the equations for each absorption sample, i.e., absorption values at different wavelengths from one sample are used to solve for the various unknowns in the equation.

[7] A refinement of the Bidigare et al. [1990] reconstruction approach was carried out by Bricaud et al. [2004] through an expansion of the number of pigment-specific in vitro absorption spectra (Figure 1). Using these expanded number of spectra and HPLC pigment measurements and an independent assessment of the package effect index, the results showed that the dominant cause of deviations from the average absorption to chlorophyll a relationships is caused by cell size distributions in the phytoplankton population, the primary factor controlling the pigment package effect.

[8] Regardless of the reconstruction methods previously used, it remains difficult to separate out the influence of 
(a)

0.01 [mg Chl a m-3] 64.57

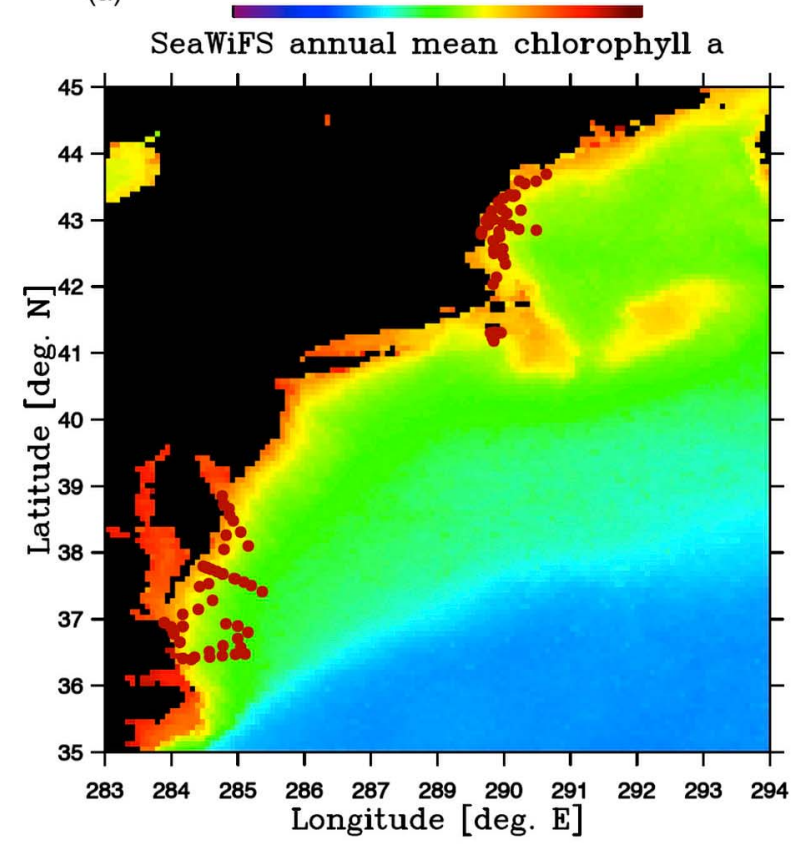

(b) 0.01 [mg Chl a m-3] 64.57

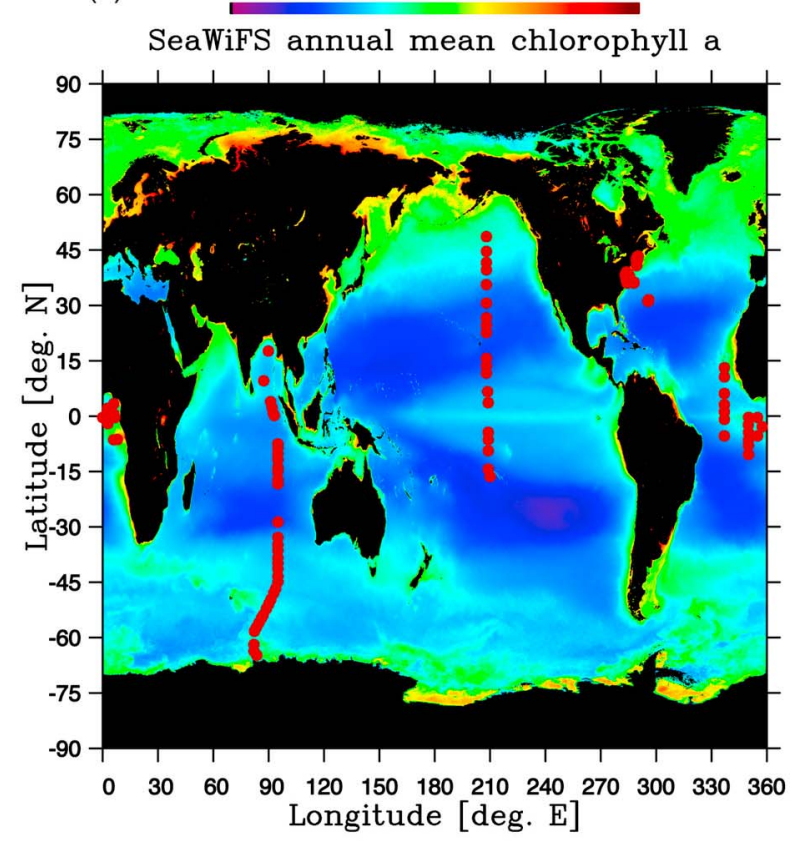

Figure 2. Map of the (a) sample locations in the Maryland and Virginia, Gulf of Maine and Cape Cod coastal regions, and (b) sample locations from these samples combined with the NASA SeaBASS samples.

pigment variability with pigment package effects since the pigment package effect is overall linked to cell size distributions and therefore phytoplankton species composition. This link in spectral absorption and dominant cell size relationship has been well demonstrated by Ciotti et al. [2002] in an attempt to use the shape of the phytoplankton absorption spectra to estimate the dominant cell size. In addition, Moisan and Mitchell [1999] have shown that the pigment package effect for a single species can cause a greater than twofold variability in phytoplankton absorption spectra due to changes in light and temperature alone.

[9] The need to understand the causes of variability in phytoplankton absorption spectra as it relates to phytoplankton pigment composition, cell size distribution and pigment package effect is obvious. Present limitations in our knowledge in this arena have placed restrictions on usage of passive remote sensing reflectance spectra from satellite, aircraft or stationary platforms. Present-day ocean inverse models [IOCCG, 2006] utilize chlorophyll-specific absorption spectra models, derived from either simple models such as a Gaussian model [Hoge and Lyon, 1996, 1999] or from inverse models [Maritorena et al., 2002], that are limited at being able to only retrieve a single phytoplankton pigment, chlorophyll a. The development of the next generation of ocean color satellites capable of hyperspectral observations (typically regarded as $5 \mathrm{~nm}$ or less spectral resolution between $400 \mathrm{~nm}$ to $700 \mathrm{~nm}$ ) will allow us to make inroads into estimating additional phytoplankton pigments and possibly functional types and size spectra.

[10] The objective of this paper is to analyze a novel and direct method of using multiple measurements of phytoplankton absorption spectra and pigments to derive pigment-specific absorption spectra that can be used to directly estimate phytoplankton pigment concentrations from phytoplankton absorption spectra. The work utilizes a range of absorption spectra and HPLC pigment measurements that have been collected in both Case I and Case II off the coasts of Maryland, Virginia, the Gulf of Maine, and Cape Cod (Figure $2 \mathrm{a}$ and Table 1.) and supplemented with additional observations obtained from the NASA SeaBASS data archive (Figure 2b). The methodology presented here can be incorporated directly into hyperspectral inverse models and employed for estimation of phytoplankton pigment concentrations. Approaches such as these, which link phytoplankton absorption spectra to pigment concentrations, are supportive of applications of future ocean color remote sensing satellite platforms (such as NASA's Geostationary Coastal and Air Pollution Events [GeoCAPE], AerosolClouds-Ecosystem [ACE], and Pre-ACE [PACE] missions)

Table 1. Related Cruise and Sample Information

\begin{tabular}{lccc}
\hline \multicolumn{1}{c}{ Cruise } & Location & Dates & $\begin{array}{c}\text { Number of } \\
\text { Samples }\end{array}$ \\
\hline $\begin{array}{l}\text { 15 COBY cross } \\
\text { shelf surveys }\end{array}$ & $\begin{array}{c}\text { VA/MD cross } \\
\text { shelf survey }\end{array}$ & Monthly from & 101 \\
BIOME 3 & $\begin{array}{c}\text { DE/MD/VA } \\
\text { coastal region }\end{array}$ & 26-30 July 2005 & 26 \\
BIOME 5 & $\begin{array}{c}\text { DE/MD/VA } \\
\text { coastal region }\end{array}$ & 9-12 May 2006 & 19 \\
MAA 1 & $\begin{array}{l}\text { Gulf of Maine } \\
\text { MAA 2 }\end{array}$ & 26-30 April 2007 & 38 \\
MAA 3 & $\begin{array}{c}\text { Gulf of Maine } \\
\text { Gulf of Maine/ }\end{array}$ & $\begin{array}{c}\text { 26-28 May 2007 } \\
\text { 6-8 June 2007 }\end{array}$ & 50 \\
SeaBASS Archive & $\begin{array}{c}\text { Martha's Vineyard } \\
\text { Global Extent }\end{array}$ & Various & 608 \\
Total Samples & & & 874 \\
\hline
\end{tabular}


Table 2. List of Pigments Used in Analysis

\begin{tabular}{|c|c|c|c|}
\hline Number & Name $^{\mathrm{a}}$ & $\begin{array}{l}\text { Field } \\
\text { Names }^{\mathrm{a}}\end{array}$ & $\begin{array}{c}\text { Pigment } \\
\text { Classification }\end{array}$ \\
\hline 1 & Chlorophyll c $(\mathrm{c} 1+\mathrm{c} 2+\mathrm{c} 3)$ & chl c & Photosynthetic \\
\hline 2 & Chlorophyllide & chlide & Degradation Produc \\
\hline 3 & Pheophorbide & phide & Degradation Produc \\
\hline 4 & Peridinin & peridinin & Photosynthetic \\
\hline 5 & 19' Butanoyloxyfucoxanthin & $\begin{array}{c}\text { but-fuco; } \\
19^{\prime} \text {-but }\end{array}$ & Photosynthetic \\
\hline 6 & Fucoxanthin & fuco & Photosynthetic \\
\hline 7 & Neoxanthin & neo & Photosynthetic \\
\hline 8 & Violaxanthin & viola & Photosynthetic \\
\hline 9 & 19' Hexanoyloxyfucoxanthin & $\begin{array}{c}\text { hex-fuco; } \\
19^{\prime} \text {-hex }\end{array}$ & Photosynthetic \\
\hline 10 & Diadinoxanthin & diadino & Photoprotective \\
\hline 11 & Alloxanthin & allo & Photosynthetic \\
\hline 12 & Diatoxanthin & diato & Photoprotective \\
\hline 13 & Zeaxanthin & zea & Photosynthetic \\
\hline 14 & Lutein & lut & Photoprotective \\
\hline 15 & $\begin{array}{c}\text { Chlorophyll b } \\
\text { (mono and di-vinyl) }\end{array}$ & chl b & Photosynthetic \\
\hline 16 & $\begin{array}{c}\text { Chlorophyll a } \\
\text { (mono and di-vinyl) }\end{array}$ & chl a & Photosynthetic \\
\hline 17 & Pheaophytin a & phytin & Degradation Product \\
\hline 18 & Carotenoids & s & $\begin{array}{l}\text { Photosynthetic and } \\
\text { Photoprotective }\end{array}$ \\
\hline
\end{tabular}

${ }^{a}$ Pigment names and field names obtained from SeaBASS Bio-Optical Archive.

that will be hyperspectral in nature and allow for the full inversion of ocean color remote sensing reflectance. The added value of hyperspectral wavelength resolution is to allow for the comprehensive description of the phytoplankton community pigment suite. These estimates could potentially be further exploited using applications such as CHEMTAX [Mackey et al., 1996] to estimate phytoplankton community composition.

\section{Methods}

\subsection{Regional U.S. East Coast Absorption Spectra and HPLC Pigment Data Set}

[11] A total of 266 water samples were collected during 20 different cruises from 2 U.S. eastern coastal ocean regions: 1) Delaware, Maryland and Virginia (149 samples), and 2) the coastal waters within the Gulf of Maine and near Martha's Vineyard (120 samples). The data set is inclusive of all seasons for the $\mathrm{DE} / \mathrm{MD} / \mathrm{VA}$ region, and of entirely spring samples from the Gulf of Maine (Table 1). All samples were gathered and processed utilizing similar methods. Water samples were collected from Niskin bottles at various depths, filtered through duplicate Whatman GFF filters, placed in Histoprep capsules, and flash frozen in liquid nitrogen for later laboratory analysis. The majority of the samples were collected in the upper few meters of the water column, a region with the greatest influence due to phytoplankton pigmentation on passive radiance sensors, such as on-board aircraft or satellites.

[12] Absorption Spectra. Phytoplankton absorption spectra samples were processed using the filter pad technique that partitions the particulate and detrital fraction [Kishino et al., 1985] to yield a phytoplankton absorption coefficient
[Mitchell, 1990]. Absorption spectra were acquired on a Perkin Elmer LS800 UV/VIS Spectrophotometer at $1 \mathrm{~nm}$ intervals from $300 \mathrm{~nm}$ to $800 \mathrm{~nm}$ using a $4 \mathrm{~nm}$ slit-width to fully resolve the spectral shape. The instrument was background corrected before each batch of six samples, and baselines were run on filtered seawater. Initial samples were run using a filtered-seawater blank for comparison to determine the absorption by all particles, $a_{p}(\lambda)$. After particulate absorption measurements were carried out, the pigments were extracted by thrice placing the filters into $10 \mathrm{~mL}$ of $100 \%$ methanol and then rinsed with filtered seawater to remove phytoplankton pigments. The filters were then rescanned in the spectrophotometer, again using a filtered seawater blank for comparison, to determine the non-pigmented, or detrital absorption $a_{d}(\lambda)$. Samples were extracted in methanol for a final 10-min period if peaks in absorption spectra appeared by the operator to be derived from residual pigments remaining in the sample. Several Beta-factors were compared using the data set from the NASA sponsored absorption workshop [Mitchell et al., 2000]. The Mitchell [1990] correction was chosen on the basis of its prediction of a good null point in the $700 \mathrm{~nm}$ region. The detrital absorption spectra $a_{d}(\lambda)$ were then subtracted from the particulate absorption $a_{p}(\lambda)$ spectra to yield the phytoplankton absorption spectra $a_{p h}(\lambda)$.

[13] High-Performance Liquid Chromatography (HPLC) Pigments. Phytoplankton pigment concentrations were measured by HPLC using the procedure described by Van Heukelem and Thomas [2001]. A total of 18 pigment groupings were identified in each of the samples (Table 2). Samples were processed in a manner similar to that for the absorption measurements and described earlier.

\subsection{Global Absorption Spectra and HPLC Pigment Data Set}

[14] An additional 608 phytoplankton absorption spectra and associated HPLC pigment measurements were obtained from the NASA SeaBASS data archive and added to the analysis data set [Werdell and Bailey, 2002; Werdell et al., 2003]. The SeaBASS archive contains over 13,692 absorption spectra measurements and of these only 7,051 were determined usable for this study after assessing the spectral resolution, noise level, and other QA/QC concerns. Only 608 of the total 7,051 available phytoplankton absorption measurements could be uniquely matched to one of the 9,631 SeaBASS archive HPLC pigment measurements. An ensemble image, inclusive of the U.S. east coast data, of the various phytoplankton absorption spectra (Figure 3) shows that a wide range of spectral shapes is observed. Because of the large number of sources of these data it is not practical to provide a level of detail on the various laboratory processing involved in obtaining the phytoplankton absorption spectra and HPLC pigment concentrations.

\subsection{Determination of Individual Pigment Absorption Spectra and Pigments}

[15] Phytoplankton pigment composition is now routinely determined using standard HPLC analysis, which yields the concentrations of the majority of pigments. By combining these pigment concentrations with pigment-specific absorption spectra, it is possible to reconstruct the phyto- 


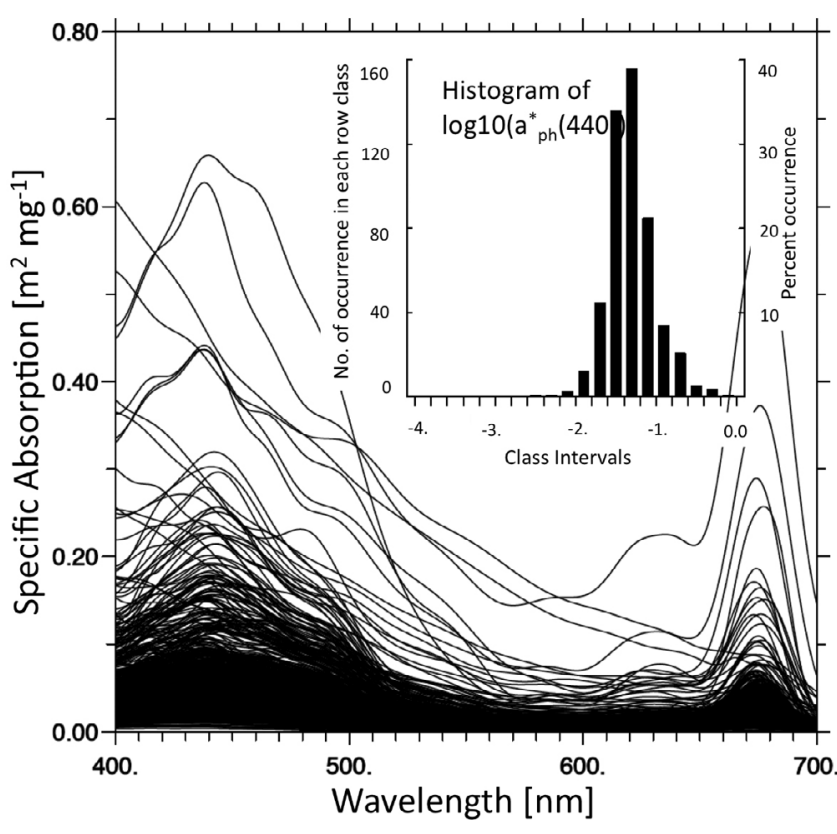

Figure 3. Composite plot of the phytoplankton specific absorption spectra for all of the samples used in the analysis. The inset is a histogram of the $\log 10$ of the specific absorption at $440 \mathrm{~nm}$.

plankton absorption spectra for the algal culture/sample, such that

$$
a_{p h}^{\prime}(\lambda)=\sum_{i=1}^{m} c_{i} a_{i}^{*}(\lambda),
$$

where $c_{i}$ is the concentration of the individual pigments derived from HPLC analysis and $a_{i}^{*}(\lambda)$ is the pigmentspecific (a.k.a. weight-specific) absorption coefficient for the phytoplankton pigment (Table 3). Bidigare et al. [1990] used this type of analysis in an attempt to reconstruct phytoplankton absorption spectra using 5 dominant pigmentspecific absorption spectra. This reconstruction technique can work well in open ocean regions where the package effect is low but typically does not work for areas such as coastal regions where the package effect is significant.
[16] When a large number of (n) related samples of phytoplankton absorption spectra and HPLC observations are available it becomes possible to relate the pigment-specific absorption coefficients and HPLC pigment concentrations to the level of phytoplankton absorption measured at a specific wavelength as

$$
\left(\begin{array}{ccc}
c_{i=1, j=1} & \cdots & c_{i=m, j=1} \\
\vdots & \ddots & \vdots \\
c_{i=1, j=n} & \cdots & c_{i=m, j=n}
\end{array}\right)\left(\begin{array}{c}
\tilde{a}_{i=1}^{*}(\lambda) \\
\vdots \\
\tilde{a}_{i=m}^{*}(\lambda)
\end{array}\right)=\left(\begin{array}{c}
a_{p h, j=1}(\lambda) \\
\vdots \\
a_{p h, j=n}(\lambda)
\end{array}\right),
$$

where $c_{i, j}$ is the observed pigment concentration of the ith pigment and the jth sample, $\tilde{a}_{i}^{*}(\lambda)$ is the derived pigmentspecific absorption for the ith pigment, and $a_{p h, j}(\lambda)$ is the measured phytoplankton absorption for the jth sample and at a given wavelength $(\lambda)$. At this point the various concentrations and absorption terms are members of a system of linear equations and can be rewritten in matrix form as,

$$
C A=A_{p h} .
$$

[17] We refer the solving the inverse of this equation to obtain an estimate of the unknown pigment-specific absorption coefficients for each of the phytoplankton pigments, $\tilde{a}_{i}^{*}(\lambda)$, as "Ensemble Sample Deconvolution" [ESD] since it requires an ensemble of related phytoplankton absorption spectra and HPLC pigment measurements for proper implementation. The resulting pigment-specific absorption functions or spectra can then be used in combination with the HPLC pigment concentrations to reconstruct the phytoplankton absorption spectra through the linear combination of the products of the individual pigment concentrations and pigment-specific absorption spectra as shown in equation (1). Care must be taken in order to avoid confusion between the pigment-specific absorption coefficients obtained through laboratory measurements with those based on this inversion technique. They are not calculated in the same manner, one is based on laboratory measurements $a_{i}^{*}(\lambda)$ and the other is a purely mathematical solution set, $\tilde{a}_{i}^{*}(\lambda)$.

[18] In this paper, we compare the results for solving equation (6) using four numerical techniques. They include: Singular Value Decomposition (SVD) [Press et al., 2007],

\begin{tabular}{|c|c|c|}
\hline Term & Definition & Units \\
\hline$a_{p}(\lambda)$ & Absorption coefficient of particles & $\mathrm{m}^{-1}$ \\
\hline$a_{d}(\lambda)$ & Absorption coefficient of methanol-extracted particles & $\mathrm{m}^{-1}$ \\
\hline$a_{p h}(\lambda)$ & Absorption coefficient of phytoplankton $\left[a_{p}(\lambda)-a_{d}(\lambda)\right]$ & $\mathrm{m}^{-1}$ \\
\hline$a_{p h}^{\prime}(\lambda)$ & Reconstructed absorption coefficient of phytoplankton & $\mathrm{m}^{-1}$ \\
\hline$a^{*}{ }_{i}(\lambda)$ & $\begin{array}{l}\text { Pigment-specific absorption coefficient of phytoplankton pigment group i obtained from absorption } \\
\text { measurement of in vitro pigment samples and corrected for shift in peaks }\end{array}$ & $\mathrm{m}^{2} \mathrm{mg}^{-1}$ \\
\hline$\tilde{a}_{i}^{*}(\lambda)$ & $\begin{array}{l}\text { Numerically estimated pigment-specific 'absorption' coefficient of phytoplankton group } i \text { obtained from } \\
\text { Ensemble Sample Deconvolution (ESD) solutions. Not a true pigment-specific absorption term. }\end{array}$ & $\mathrm{m}^{2} \mathrm{mg}^{-1}$ \\
\hline$\hat{a}_{p h}^{*}(\lambda)$ & Absorption coefficient of phytoplankton normalized to the 'unpackaged' absorption estimates at $675 \mathrm{~nm}$ & $\mathrm{~m}^{-1}$ \\
\hline$c_{i}$ & Concentration of phytoplankton pigment group $i$ & $\mathrm{mg} \mathrm{m}^{-3}$ \\
\hline$a_{\text {sol }}(\lambda)$ & Absorption coefficient of phytoplankton in the absence of the pigment package effect & $\mathrm{m}^{-1}$ \\
\hline$a_{m i s s}(\lambda)$ & Absorption coefficient of missing & \\
\hline$\alpha$ & Value of missing absorption coefficient at $675 \mathrm{~nm}$ & $\mathrm{~m}^{-1}$ \\
\hline$\varphi$ & Power function term in 'missing' absorption coefficient model & n.d. \\
\hline
\end{tabular}
Non-Negative Least squares (NNLS) [Lawson and Hanson,

Table 3. Definition of Various Terms 
1974] and two Nonlinear Least Squared Minimization schemes (MRQMIN [Levenberg, 1944; Marquardt, 1963; Press et al., 2007] and LMDIF [Hiebert, 1980]). The utility of these numerical methods is that they are not impacted by potential spectral shifts of individual pigment absorption curves that does occur with direct absorption measurements of individual pigments dissolved in a solvent such as methanol, as pointed out by Bidigare et al. [1990] and Bricaud et al. [2004]. In addition, these methods estimate the in vivo rather than in vitro pigment-specific absorption spectra, thereby explicitly including pigment package effects.

[19] Singular Valued Decomposition (SVD). The first of these methods is approached by taking the inverse of $\mathrm{C}$, thereby making it possible to directly solve the matrix equation in order to determine unique absorption spectra for individual pigments such that

$$
C^{-1}(C A)=C^{-1} A_{p h}=I_{n} A=A .
$$

In practice, because of the difficulties of direct matrix inversion and problems related to singular matrices, the approach to this method is often to use the Singular Value Decomposition (SVD) methodology in order to solve for the unknown pigment-specific absorption values. A thorough presentation of this method is found in the work by Press et al. [2007].

[20] The pitfalls that can occur in the SVD approach is that the solution set cannot be guaranteed to be completely positive, so that negative 'absorption' values can result. One needs to approach the results from such analysis with an understanding that these negative values are not related to something akin to fluorescence but are related to the solution noting a negative influence from that specific pigment in relation to the measured phytoplankton absorption at that wavelength. While the units of the solutions are in $\mathrm{m}^{2} \mathrm{mg}^{-1}$, the values must be thought of as a component to the phytoplankton absorption value and not a separate process.

[21] Non-Negative Least squares (NNLS). In order to address the issue of possible negative absorption coefficients within the solution, a second method called Non-Negative Least squares [Lawson and Hanson, 1974] is carried out. In this approach, the previous linear system of equations is reformulated to

$$
\text { minimize }\left\|C A-A_{p h}\right\| \quad \text { subject to } A \geq 0 .
$$

The details to this technique are presented by Lawson and Hanson [1974]. The essence of the technique is that a solution is found for the various unknown pigment-specific absorption coefficients, $\tilde{a}_{i}^{*}(\lambda)$ in a manner similar to the SVD technique but with the caveat that all the coefficients are positive.

[22] Nonlinear Least-Squared Minimization (MRQMIN/ LMDIF). A third strategy that is used to obtain estimates of the pigment-specific absorption spectra is to apply a nonlinear minimization algorithm to the Sum of Squared Error (SSE) between the total absorption and the estimated total absorption such that the

$$
S S E=\sum_{j=1}^{n}\left(a_{p h, j}(\lambda)-\sum_{i=1}^{m} c_{i, j}\left|\tilde{a}_{i}^{*}(\lambda)\right|\right)^{2} .
$$

By including a large number of field samples (n) that have been analyzed for absorption spectra and the suite of HPLC pigments, it is possible to develop the pigmentspecific absorption spectra through the solution of these matrix equations at each wavelength. Taking the absolute values of the pigment-specific absorption coefficients forces the solutions to be positive. Two different algorithms are implemented. This nonlinear minimization scheme is called Levenberg-Marquardt [Levenberg, 1944; Marquardt, 1963] and is implemented using both the MRQMIN algorithm described by Press et al. [2007] and the LMDIF algorithm developed at Argonne National Laboratory [Hiebert, 1980].

[23] The complete set of 874 phytoplankton absorption spectra and pigment HPLC measurements are used to derive specific absorption coefficients using the three (SVD, NNLS, MRQMIN/LMDIF) methods outlined above. One set was created using solely the 266 samples from the U.S. east coast data set and the other from a combination of the full 874 observations, allowing for a comparison of regional versus global solutions. These are presented in the results section. The purpose of using multiple inverse model applications (SVD, NNLS, MRQMIN/LMDIF) is to verify that the inverse model solutions are robust and not influenced by the choice of matrix inversion application. Vallino [2000] used 12 different minimization schemes to optimize a system of coupled ordinary differential equations that simulated an ocean ecosystem. All of the minimization schemes converged on different model parameter sets.

\subsection{Estimation of HPLC Pigment Concentrations}

[24] Once estimates for pigment-specific absorption coefficients are available, either through laboratory measurements [Bidigare et al., 1990; Bricaud et al., 2004] or through numerical analysis such as the ESD approaches outlined above, it becomes possible to combine those with phytoplankton absorption spectra in order to estimate the HPLC pigment concentrations. By expanding upon the phytoplankton absorption spectra reconstruction technique of Bidigare et al. [1990], the phytoplankton absorption can be written as

$$
\left(\begin{array}{ccc}
\tilde{a}_{i=1}^{*}(\lambda=1) & \ldots & \tilde{a}_{i=M}^{*}(\lambda=1) \\
\vdots & \ddots & \vdots \\
\tilde{a}_{i=1}^{*}(\lambda=L) & \ldots & \tilde{a}_{i=M}^{*}(\lambda=L)
\end{array}\right)\left(\begin{array}{c}
\tilde{c}_{j=1} \\
\vdots \\
\tilde{c}_{j=M}
\end{array}\right)=\left(\begin{array}{c}
a_{p h}(\lambda=1) \\
\vdots \\
a_{p h}(\lambda=L)
\end{array}\right)
$$

where $\tilde{a}_{i}^{*}(\lambda)$ is the estimated pigment-specific absorption of the ith pigment at a specific measured wavelength, $\tilde{c}_{j}$ is the estimated concentration of pigment $\mathrm{j}$, and $a_{p h}(\lambda)$ is the total measured absorption due to phytoplankton. At this point the equations are a system of linear equations and can be rewritten in matrix form as,

$$
A \tilde{C}=A_{p h},
$$

where the matrix $\mathrm{A}$ is the set of pigment-specific absorption coefficients, $\tilde{C}$ is the array of pigment concentrations to be 

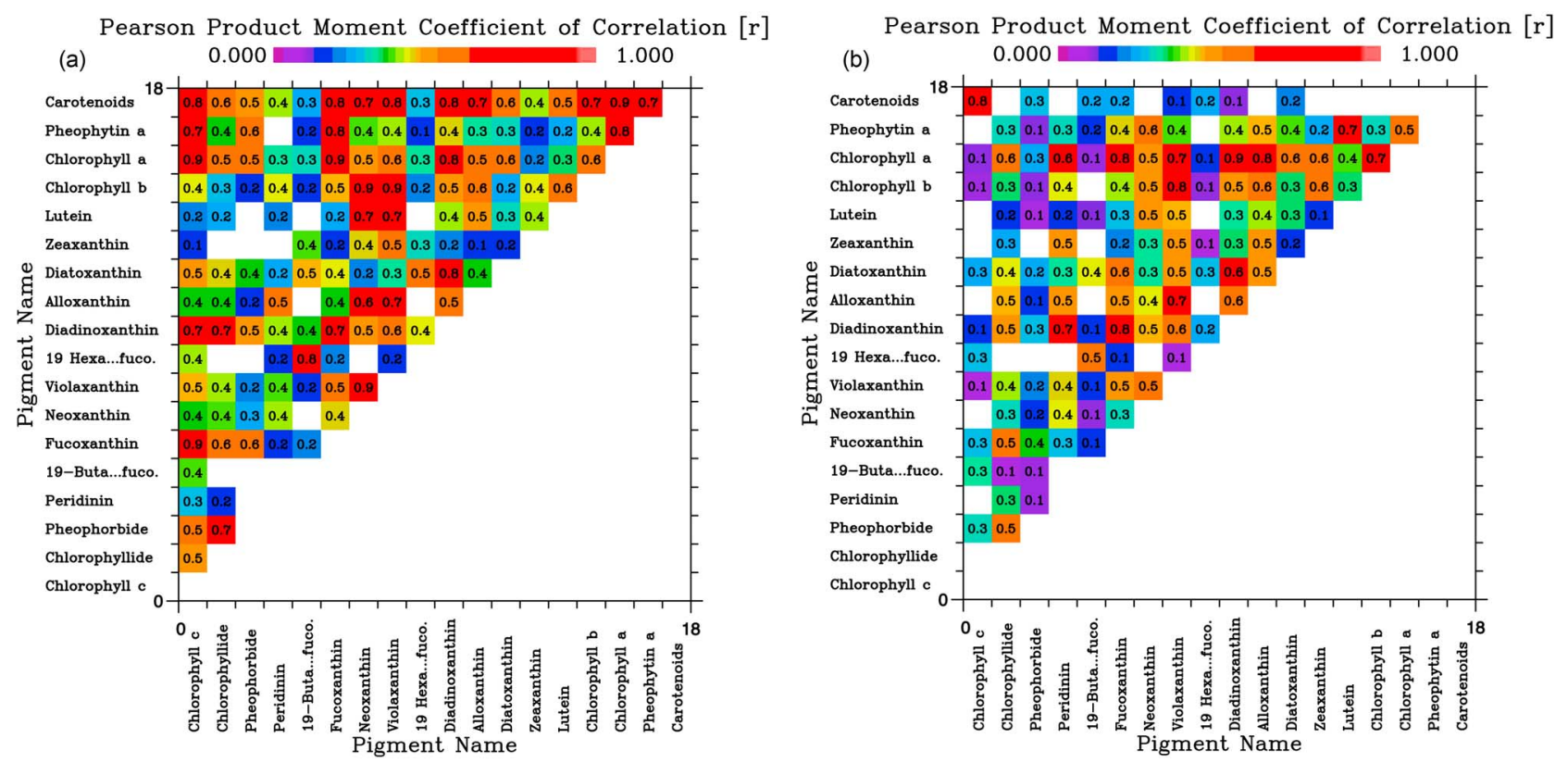

Figure 4. Plot showing the Pearson Product Moment Coefficient of Correlation. The names of the various pigment types are shown along the bottom and left of the plot. The color bar scale is linear. Truncated correlation values are written within the associated color block and those correlation values that are not significantly greater than zero are left blank.

estimated and $A_{p h}$ is the phytoplankton absorption spectra. At this point the equation looks similar to that of equation (6) and so similar inversion techniques can be applied to estimate the HPLC pigment concentrations using phytoplankton absorption spectra measurements.

[25] In practice, independent data sets were created by randomly splitting the U.S. east coast (266 samples) and global (874 samples), into two halves each. Phytoplankton absorption spectra and HPLC observations from one of the splits was used to calculate the pigment-specific absorption spectra. The results from this inversion were used with the phytoplankton absorption spectra from the second split data set to obtain an independent estimate of the phytoplankton pigment suites which were then compared to the HPLC observations from the second split.

\section{Results}

\subsection{HPLC Pigment Correlation}

[26] The Pearson Product Moment Coefficient of Correlation, $r$, is calculated for each set (U.S. east coast and combined global) of HPLC pigment observations (Figure 4). Correlations between pigments from the U.S. east coast data set (Figure 4a) were much higher overall than that observed within the larger global HPLC data set (Figure 4b). High levels of correlation between pigments is a concern because it can cause multiple inverse model solutions.

\subsection{Pigment-Specific Absorption Spectra/Coefficients}

[27] Four different solution sets were obtained from carrying out the inversion to obtain pigment-specific absorption spectra, one for each of the numerical methods applied (SVD, NNLS, MRQMIN, LMDIF). Solutions for the SVD and NNLS are shown in Figures 5a and 5b, respectively. In the SVD application, negative coefficients are possible because the method is a pure matrix inversion. The other three applications (NNLS, MRQMIN, and LMDIF) are nonlinear least square applications that allows the solutions to be constrained to be positive. What is obvious when comparing between the four solutions is that: i) the SVD solution contains negative values; ii) only the SVD and NNLS solutions vary smoothly across the spectra; iii) the NNLS, MRQMIN and LMDIF solutions show similar spectral shapes with carotenoid having the largest specificabsorption levels overall; and, iv) the carotenoid specificabsorption is almost an order of magnitude higher than any of the laboratory measured in vitro specific-absorption spectra (Figure 1). In addition to the variability between the solution sets, it needs to be pointed out that the solutions are obtained by fitting 'packaged' absorption spectra to the 'unpacked' HPLC pigment measurements. Because HPLC pigment observations show high levels of correlations between various pigments and because of the wide range in possible levels of pigment package effect there should be no expectations that the various pigment absorption spectra model solutions would reflect those obtained from laboratory measurements, such as shown in Figure 1.

[28] The various solutions to the pigment-specific absorption spectra were used with the observed HPLC pigment measurements in equation (1) to reconstruct the phytoplankton absorption spectra in order to provide for a way to quantitatively assess the ability of these inverse model solutions (Figure 6). In addition to these solutions, a 'baseline' solution was established using the pigmentspecific absorption spectra from Bricaud et al. [2004]. The coefficient of determination $\left(\mathrm{r}^{2}\right)$ for each of these solutions as a function of wavelength is shown in Figure 7. The 
(a)

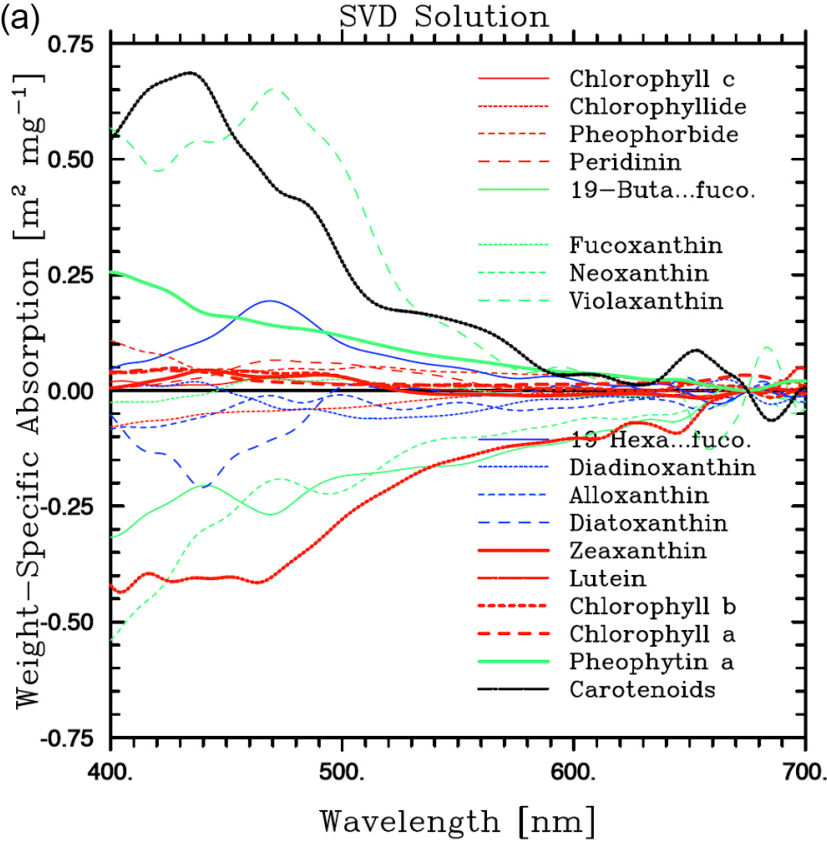

(b)

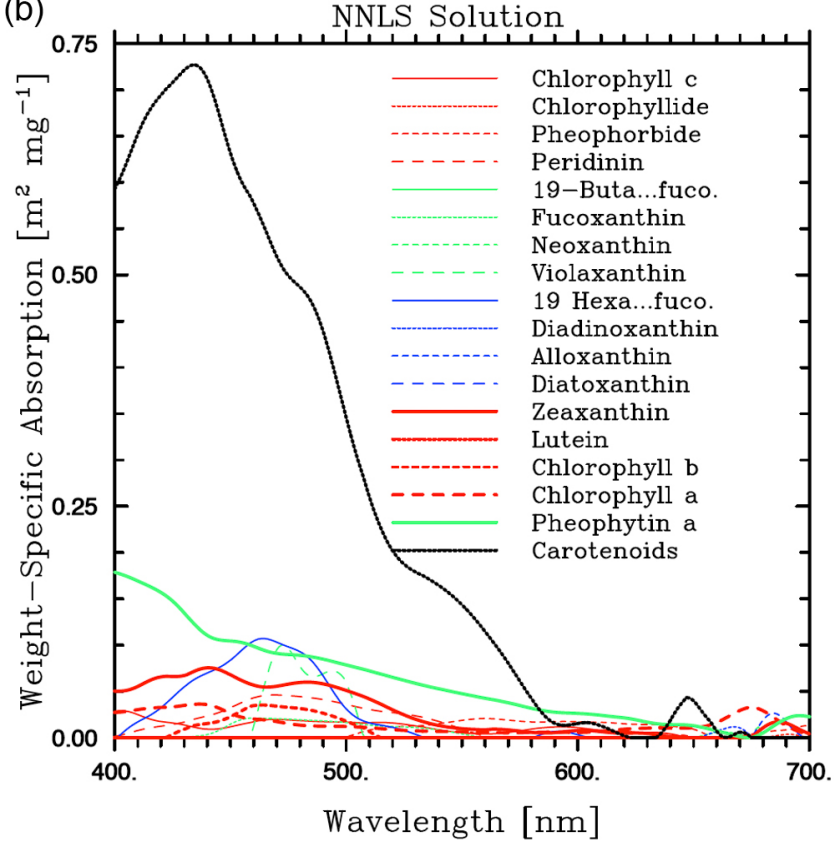

Figure 5. Pigment-specific absorption spectra/modes for the 18 pigments analyzed in this study obtained from the (a) SVD, and (b) NNLS algorithms. Solutions for the MRQMIN and LMDIF algorithms (not shown) are similar to that of the NNLS solution.

baseline solution using the Bricaud et al. [2004] pigmentspecific absorption spectra is limited to the spectral range of 400 to $700 \mathrm{~nm}$, whereas reconstructions from the four inversions can extend into the UV region. All inverse model solutions show a dramatic increase in the ability to reconstruct the total phytoplankton absorption spectra relative to the baseline Bricaud et al. [2004] reconstructions. The SVD solutions, though seemingly limited due to its rendering of negative absorption coefficients, outperform the three other inversion algorithms (NNLS, MRQMIN, and LMDIF). The three least squares inversion algorithms show very similar linear regressions slopes and confidence intervals (Figure 7a) and coefficients of determination (Figure 7b). All solutions, including the SVD and 'baseline' reconstruction show a marked decrease in $r^{2}$ values in the range of 550 to $600 \mathrm{~nm}$. The correlations and normalized standard deviations of the various inverse model solutions (Figure 8) shows that the correlations for all of the solutions is high $(>0.9)$ and that the standard deviations are slightly lower than the observations.

[29] Much of the present difficulty of successful spectral inversions is due to the influence of the pigment package effect on phytoplankton absorption spectra. This phenomenon can be observed by comparing the absolute absorption measured at $675 \mathrm{~nm}$ with the concentration of chlorophyll a, which is the primary absorbing pigment at that wavelength (Figure 9). The falloff from the 'expected' reconstructed absorption levels (shown as the black line in Figure 9 and having a slope equal to the chlorophyll a-specific absorption

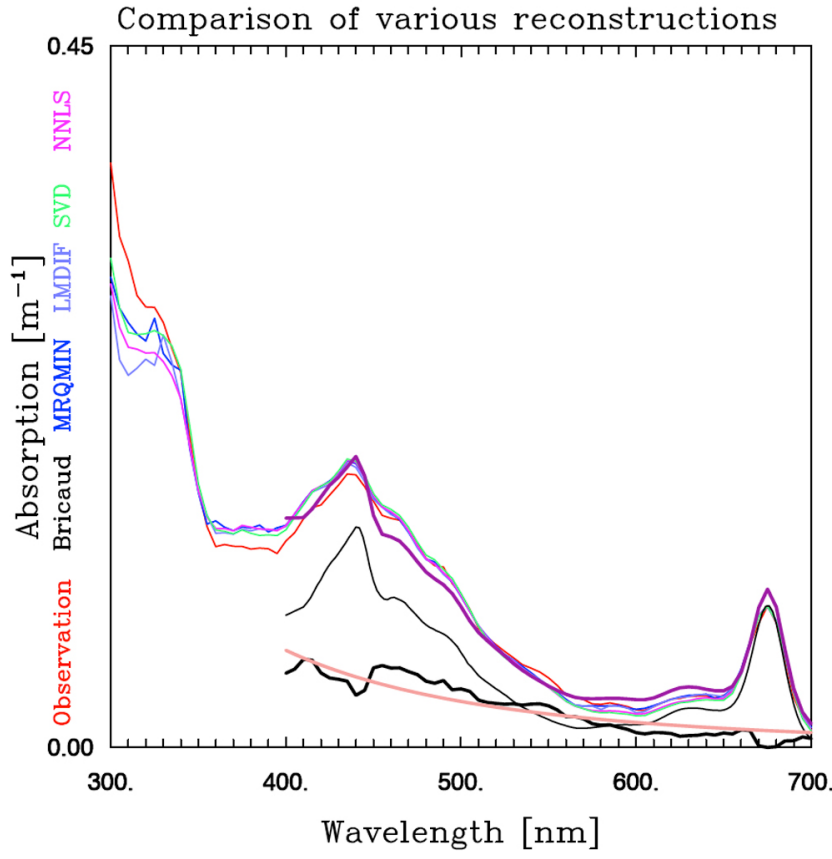

Figure 6. A comparison of the absorption spectra observations (red curve) and six absorption spectra reconstructions for one of the 792 absorption spectra and pigment observation pairs. The SVD, MRQMIN, LMDIF and NNLS solutions (thin green, teal, light and dark blue curves, respectively) extend across the full 300 to $700 \mathrm{~nm}$ spectral range. The difference (thick black curve) between the observations (thin red curve) and the Bricaud et al. [2004] reconstruction (thin black curve ranging from 400 to $700 \mathrm{~nm}$ ) appears to look like a power function. This difference is the 'missing absorption term' that was modeled using a power function (thick mauve curve). The sum (thick purple curve) of the standard Bricaud et al. [2004] (thin black curve) reconstruction and the fitted power function (thick black curve) compares very well to the observations. 
at $675 \mathrm{~nm}$ ) is primarily a result of the pigment package effect. In order to assess this, all the measured phytoplankton absorption were normalized to $675 \mathrm{~nm}$ by multiplying the absorption spectra by a normalization term that can be thought of as the inverse pigment package effect term at $675 \mathrm{~nm}$, such that the spectra unpackaged, relative to $675 \mathrm{~nm}$, or 'normalized' absorption spectra,

$$
\hat{a}_{p h}(\lambda)=a_{p h}(\lambda)\left(\frac{\sum_{i=1}^{m} c_{i} a_{i}^{*}(675 \mathrm{~nm})}{a_{p h}(675 \mathrm{~nm})}\right)=a_{p h}(\lambda) \frac{a^{\prime}(675 \mathrm{~nm})}{a_{p h}(675 \mathrm{~nm})} .
$$

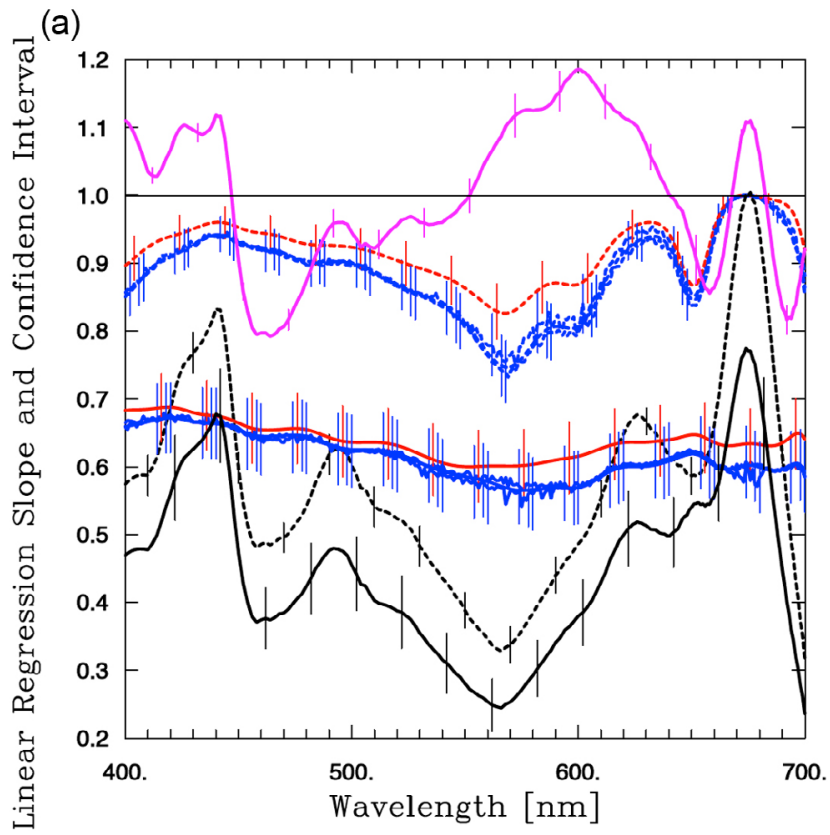

(b)

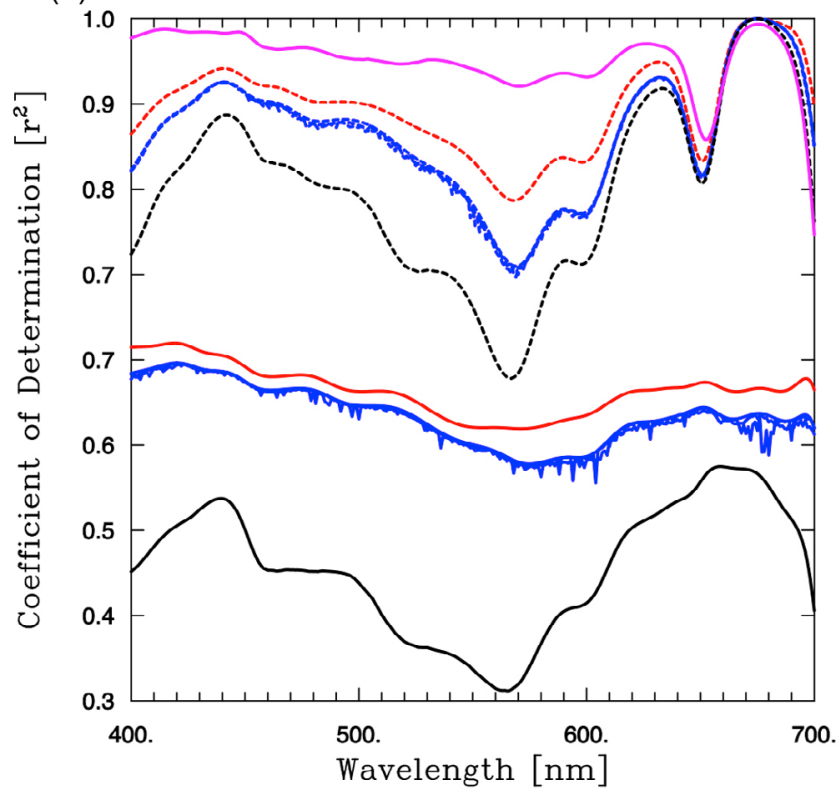

[30] Estimates for $a^{\prime}(\lambda=675 \mathrm{~nm})$ were obtained using pigment-specific absorption values from Bricaud et al. [2004]. Once all of the absorption spectra were 'normalized' (Figure 10) the various inversion algorithms described above (SVD, NNLS, MRQMIN, LMDIF) were reapplied to these 'normalized' absorption spectra. The statistical analysis on the resulting absorption spectra (Figures $7 \mathrm{a}$ and $7 \mathrm{~b}$ ) shows a dramatic improvement as compared to those obtained from inversions done using the original measured absorption spectra. Using this as a guide, the Bidigare et al. [1990] model was reformulated to include this 'normalization' term (equation (12)) such that the modified the reconstructed absorption spectra,

$$
a_{p h}^{\prime}(\lambda)=\frac{a_{p h}(675 \mathrm{~nm})}{\sum_{i=1}^{m} c_{i} a_{i}^{*}(675 \mathrm{~nm})} \sum_{i=1}^{m} c_{i} a_{i}^{*}(\lambda)
$$

The spectral reconstructions carried out by Bricaud et al. [2004] systematically showed lower absorption than the measured absorption spectra, leading them to argue that a missing absorption material was present in the phytoplankton samples. This is also true for many of the absorption spectra in our data set. In the majority of the samples from this study, the spectral reconstructions following Bricaud et al. [2004] showed higher absorption than the measured absorption spectra. This difference is expected since the Bricaud et al. [2004] samples were primarily obtained in open ocean settings, where the pigment package effect is minimal and a majority of the samples analyzed in this present study are from coastal ocean areas where the pigment package effect is often very significant. However, upon reconstruction of the absorption spectra using equation (13), which is equivalent to 'normalization' of the absorption spectra to $675 \mathrm{~nm}$ (Figure $10)$, the spectral reconstructions show lower absorption than the measured absorption spectra.

Figure 7. The (a) slopes and confidence intervals, and (b) coefficient of determination $\left(\mathrm{r}^{2}\right)$ from comparison of the reconstructed versus measured phytoplankton absorption spectra for all samples. The 'baseline' level from using the Bricaud et al. [2004] absorption spectra (black curve) is limited to between 400 to $700 \mathrm{~nm}$. The SVD solutions (red curves) are shown for solutions to the reconstructions using the raw (solid red curve) versus spectra normalized to $675 \mathrm{~nm}$ (dashed red curve). The NNLS, MRQMIN and LMDIF solutions (blue curves) are shown for solutions to the reconstructions using the raw (solid blue curves) versus the spectra normalized to $675 \mathrm{~nm}$ (dashed blue curves). The $\mathrm{r}^{2}$ values of spectral reconstructions using the Bricaud et al. [2004] to total phytoplankton absorption spectra 'normalized' to $675 \mathrm{~nm}$ (dashed black curves) also show a dramatic improvement over the 'baseline' reconstructions (solid black curves). Further improvements to this modified reconstruction are possible by fitting the coefficients to a logarithmic model for the observed missing absorption component (solid fuchsia curves). 


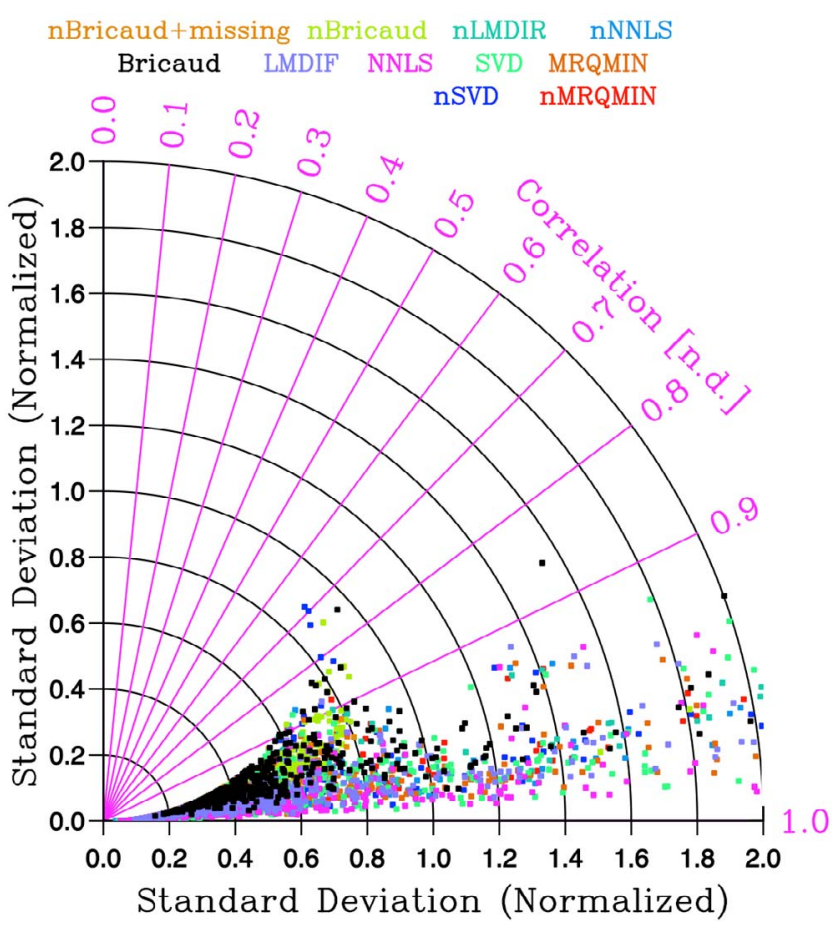

Figure 8. Taylor plot of the reconstructed phytoplankton absorption spectra normalized to the observations. The color of the dots indicates the type of inverse model technique used. See Tables 4 or 5 for a listing.

[31] Inspection of the difference between the 'normalized' measured absorption and the reconstruction spectra shows that the gross spectral shape of this missing absorption resembles a logarithmic function,

$$
a_{\text {miss }}(\lambda)=\alpha\left(\frac{675 \mathrm{~nm}}{\lambda}\right)^{\varphi} .
$$

In order to diagnose this further, the original Bidigare et al. [1990] total absorption spectra reconstruction equation (equation (1)) was further modified to include these new terms such that

$$
a_{p h}^{\prime}(\lambda)=\frac{a_{p h}(675 \mathrm{~nm})}{\alpha+\sum_{i=1}^{m} c_{i} a_{i}^{*}(675 \mathrm{~nm})}\left(\alpha\left(\frac{675 \mathrm{~nm}}{\lambda}\right)^{\varphi}+\sum_{i=1}^{m} c_{i} a_{i}^{*}(\lambda)\right) .
$$

[32] This equation was used with the observations of phytoplankton absorption and pigment concentration to fit the two parameters $(\alpha, \varphi)$ in the missing absorption term, resulting in a dramatic increase $\left(\mathrm{r}^{2}>0.98\right)$ in the ability to reconstruct phytoplankton absorption spectra (Figures 7a and $7 \mathrm{~b}$ ). In addition, one coefficient, $\alpha$, shows strong correlation with the chlorophyll a (Figure 11) while the slope of the logarithm, $\varphi$, (not shown) did not.

[33] Estimation of the pigment package effect at $675 \mathrm{~nm}$ has previously been done by Nelson et al. [1993] by using the quotient of the reconstructed versus the measured absorption values at $675 \mathrm{~nm}$ and this method of estimation has been further argued by Bricaud et al. [2004] which notes that the "package effect index,"

$$
Q_{a}^{*}(\lambda)=\frac{a_{p h}(\lambda)}{a_{s o l}(\lambda)},
$$

where $a_{p h}(\lambda)$ is the actual absorption coefficient and $a_{s o l}(\lambda)$ is the absorption coefficient from the same material when dispersed within a solution [Morel and Bricaud, 1981]. By making use of the fully reconstructed solutions through the modification of equation (16) to remove the 'normalization' term, the pigment package effect can be estimated as,

$$
Q_{a}^{*}(\lambda)=\frac{a_{p h}(\lambda)}{a_{s o l}(\lambda)}=\frac{a_{p h}(\lambda)}{\alpha\left(\frac{675 \mathrm{~nm}}{\lambda}\right)^{\varphi}+\sum_{i=1}^{m} c_{i} a_{i}^{*}(\lambda)}
$$

for the entire visible spectrum (Figure 12). When the missing absorption components are accounted for in the absorption spectra, the estimated pigment package effect term shows little spectral variability and ranges between samples across its full range of 0 to 1 , with a mean near 0.5 , such that for any one spectra

$$
Q_{a}^{*}(\lambda) \approx \frac{a_{p h}(675 \mathrm{~nm})}{\alpha+\sum_{i=1}^{m} c_{i} a_{i}^{*}(675 \mathrm{~nm})} \approx \text { const. }
$$

When the pigment package effect is calculated using equation (16) and the initial reconstructed phytoplankton absorption spectra the values are often higher than 1 and show much more variability across the spectra.

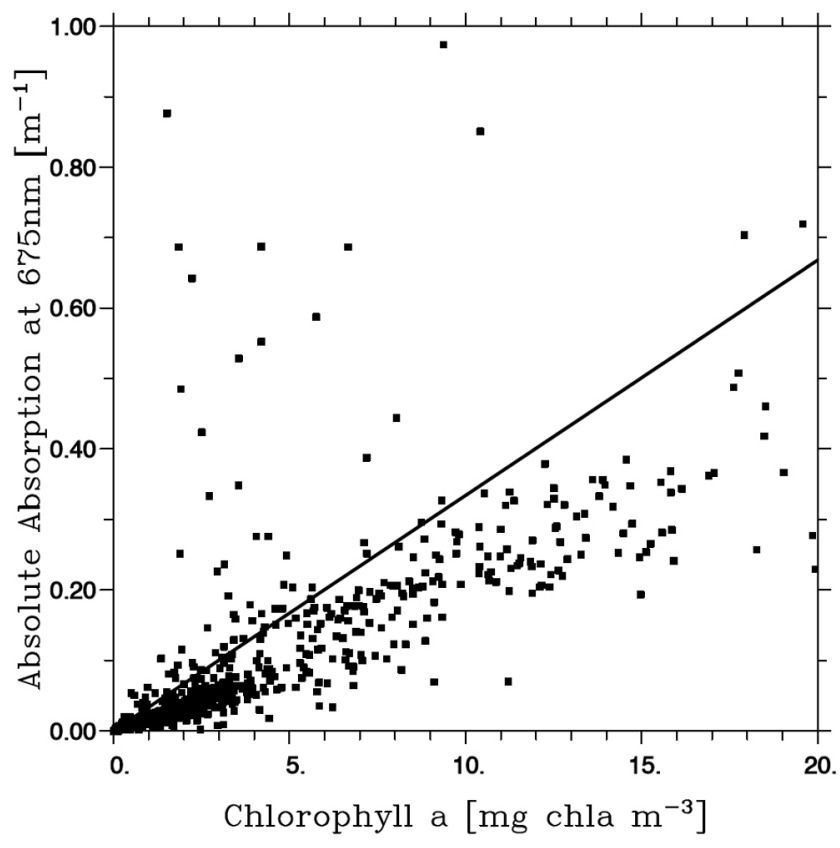

Figure 9. Observed phytoplankton absorption levels at $675 \mathrm{~nm}$ versus chlorophyll a concentrations. The line denotes the expected level of absorption from unpackaged chlorophyll a absorption. 


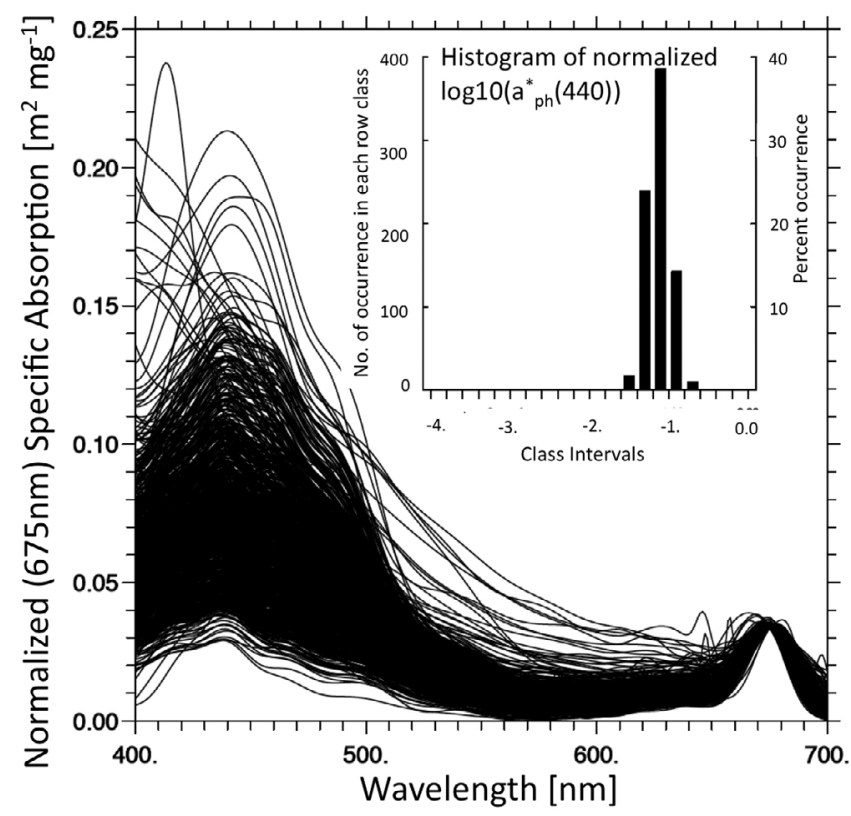

Figure 10. Composite plot of the phytoplankton absolute absorption spectra normalized to $675 \mathrm{~nm}$ for all of the samples used in the analysis.

\subsection{Inversion of the Pigment-Specific Absorption Spectra to Estimate Phytoplankton Pigments}

[34] A goal in modeling phytoplankton absorption spectra is to make use of the reconstruction models to estimate phytoplankton pigments directly from the phytoplankton absorption spectra (equation (11)). The same numerical

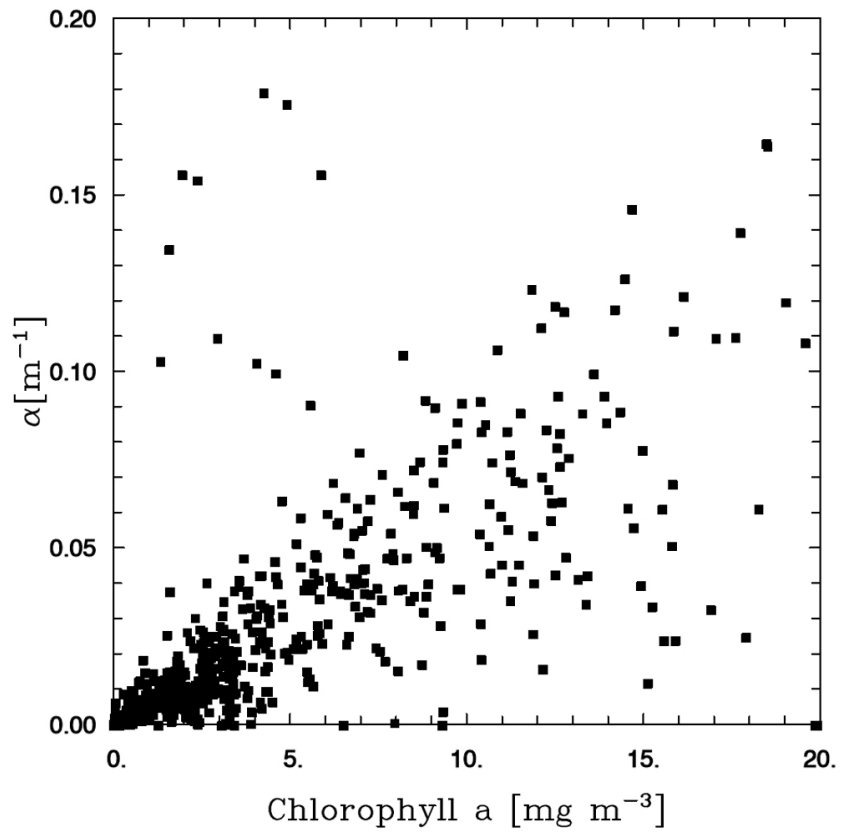

Figure 11. Magnitude of the missing absorption term, $\alpha$, versus the observed HPLC chlorophyll $a$ concentrations. This term is the absolute level of missing absorption at $675 \mathrm{~nm}$. inversion techniques used to solve for the pigment-specific absorption spectra can also be used to solve these sets of equations. A set of five inverse model solutions was carried out on both the raw and 'normalized' total absorption spectra. These include: a) SVD, b) SVD-NNLS (which solved the equations using the NNLS technique on the smooth pigmentspecific absorption spectra solutions from the SVD inversion, c) NNLS, d) MQRMIN, and e) LMDIF. The coefficients of determination $\left(\mathrm{r}^{2}\right)$ are shown in Table 4 for all solutions using the U.S. east coast (COBY+BIOME+MAA) observations and in Table 5 for all solutions using the combination of all observations (SeaBASS+COBY+BIOME+MAA). The pigment-specific absorption spectra required for the inverse models was obtained from the inverse model solutions for these spectra using a randomly split portion of the full data set. The measured absorption spectra and HPLC pigments from the other part of the data was used to independently validate the inverse model solutions.

[35] U.S. East Coast Pigment Estimates: In all cases, the concentrations being estimated reflect those measured in the HPLC pigment analysis. Chlorophyll a, carotenoids, fucoxanthin, violaxanthin, diadinoxanthin and peridinin all show some level of adequate correlations $\left(r^{2}>0.6\right)$, though fucoxanthin and the carotenoids are the only two pigments that are retrieved consistently across all the inversion methods. Chlorophyllide, alloxanthin, diatoxanthin, zeaxanthin, lutein and chlorophyll $b$ all have poor $r^{2}$ values. Finally, both 19'-butanoyloxyfucoxanthin (but-fuco) and 19'-hexanoyloxyfucoxanthin (hex-fuco), two poorly correlated pigments in the HPLC measurements (Figure 4) also had very poor retrievals across all inversions. Inversion solutions that used the $675 \mathrm{~nm}$ normalized spectra had much better predictions of pigments, with chlorophyll a values being almost exact.

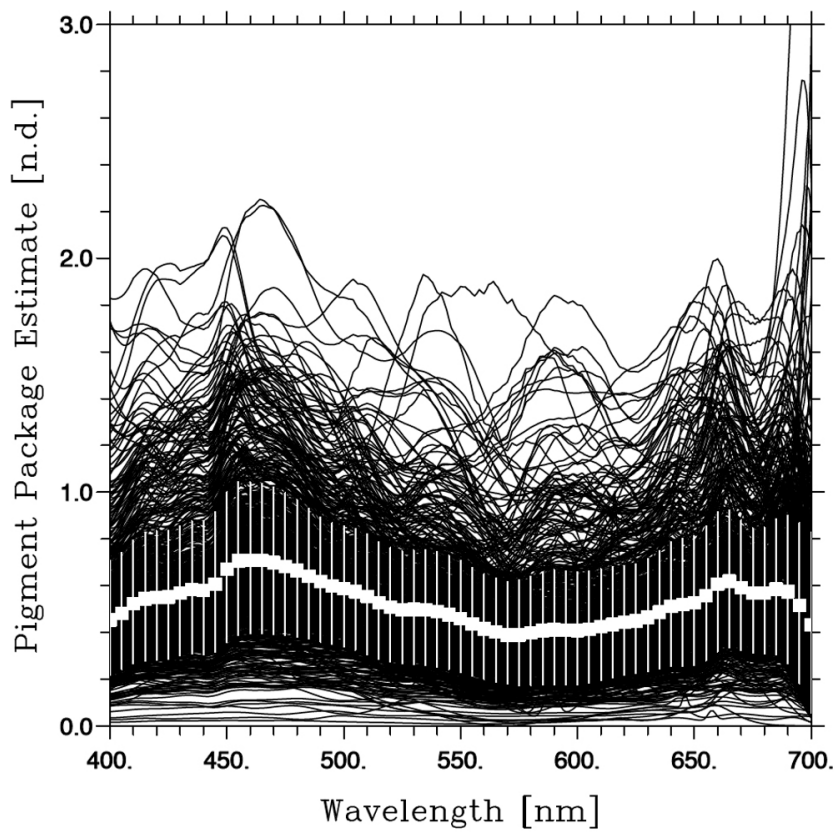

Figure 12. Estimates of the pigment package effect for all samples calculated using the ratio of measured in vivo absorption to modeled in vitro absorption spectra. 
Table 4. Coefficient of Determination $\left(\mathrm{r}^{2}\right)$ Levels for Retrieval of Pigment Concentrations Using Only the COBY, BIOME and MAA Data Sets ${ }^{\mathrm{a}}$

\begin{tabular}{|c|c|c|c|c|c|c|c|c|c|c|c|c|}
\hline \multirow[b]{2}{*}{$\begin{array}{l}\text { Pigment } \\
\text { Name }\end{array}$} & \multicolumn{5}{|c|}{ Raw } & \multicolumn{2}{|c|}{ Auto-Normalized $^{\mathrm{b}}$} & \multicolumn{5}{|c|}{ Normalized to $675 \mathrm{~nm}$} \\
\hline & SVD & SVD-NNLS & NNLS & MRQMIN & LMDIF & Bricaud & $\begin{array}{c}\text { Bricaud + } \\
\text { Missing }\end{array}$ & SVD & SVD-NNLS & NNLS & MRQMIN & LMDIF \\
\hline chlorophyll c (c1+c2+c2) & 0.56 & 0.69 & 0.27 & 0.38 & 0.40 & 0.89 & 0.57 & 0.78 & 0.86 & 0.48 & 0.38 & 0.47 \\
\hline chlorophyllide & 0.36 & 0.47 & 0.23 & 0.47 & 0.05 & (b) & (b) & 0.42 & 0.45 & 0.05 & 0.00 & 0.01 \\
\hline pheophoribide & 0.51 & 0.59 & 0.22 & 0.24 & 0.23 & (b) & (b) & 0.45 & 0.58 & 0.31 & 0.49 & 0.25 \\
\hline Peridinin & 0.60 & 0.65 & 0.54 & 0.52 & 0.47 & 0.16 & 0.25 & 0.48 & 0.60 & 0.30 & 0.29 & 0.36 \\
\hline 19' butanoy-loxyfucoxanthin & 0.31 & 0.42 & 0.53 & 0.46 & 0.56 & 0.01 & 0.10 & 0.39 & 0.52 & 0.50 & 0.30 & 0.69 \\
\hline fucoxanthin & 0.84 & 0.87 & 0.78 & 0.80 & 0.80 & 0.94 & 0.70 & 0.89 & 0.93 & 0.58 & 0.65 & 0.59 \\
\hline neoxanthin & 0.36 & 0.41 & 0.27 & 0.43 & 0.37 & (b) & (b) & 0.45 & 0.57 & 0.33 & 0.36 & 0.39 \\
\hline violaxanthin & 0.63 & 0.72 & 0.53 & 0.63 & 0.57 & (b) & (b) & 0.47 & 0.74 & 0.43 & 0.07 & 0.29 \\
\hline $19^{\prime}$ hexanoy-loxyfucoxanthin & 0.30 & 0.40 & 0.00 & 0.40 & 0.17 & 0.31 & 0.14 & 0.37 & 0.52 & 0.01 & 0.13 & 0.15 \\
\hline diadinoxanthin & 0.71 & 0.71 & 0.37 & 0.41 & 0.42 & 0.74 & 0.51 & 0.73 & 0.74 & 0.42 & 0.29 & 0.24 \\
\hline alloxanthin & 0.31 & 0.41 & 0.11 & 0.01 & 0.20 & 0.50 & 0.30 & 0.48 & 0.58 & 0.13 & 0.18 & 0.12 \\
\hline diatoxanthin & 0.15 & 0.26 & 0.00 & 0.01 & 0.01 & (b) & (b) & 0.25 & 0.45 & 0.32 & 0.05 & 0.30 \\
\hline zeaxanthin & 0.36 & 0.44 & 0.18 & 0.22 & 0.01 & 0.06 & 0.20 & 0.27 & 0.34 & 0.04 & 0.00 & 0.01 \\
\hline lutein & 0.20 & 0.26 & 0.27 & 0.18 & 0.08 & (b) & (b) & 0.18 & 0.18 & 0.07 & 0.24 & 0.32 \\
\hline chlorophyll $b^{c}$ & 0.27 & 0.33 & 0.23 & 0.46 & 0.38 & 0.00 & 0.15 & 0.28 & 0.53 & 0.41 & 0.34 & 0.42 \\
\hline chlorophyll $\mathrm{a}^{\mathrm{c}}$ & 0.76 & 0.81 & 0.59 & 0.36 & 0.39 & $\mathrm{NA}^{\mathrm{d}}$ & $\mathrm{NA}^{\mathrm{d}}$ & 1.00 & 1.00 & 0.98 & 0.86 & 0.96 \\
\hline phaeophytin a & 0.59 & 0.65 & 0.53 & 0.45 & 0.48 & (b) & (b) & 0.63 & 0.72 & 0.37 & 0.48 & 0.42 \\
\hline carotenoids & 0.74 & 0.83 & 0.78 & 0.83 & 0.79 & 0.57 & 0.00 & 0.92 & 0.94 & 0.68 & 0.83 & 0.78 \\
\hline
\end{tabular}

${ }^{\mathrm{a}}$ Values greater than 0.5 are in bold.

${ }^{\mathrm{b}}$ Entries with (b) indicate pigment not included in inversion due to lack of pigment-specific absorption coefficients.

Includes both mono and divinyl.

${ }^{\mathrm{d}}$ Inversion solutions normalized against chlorophyll a values, making correlations irrelevant.

[36] Because of the very good agreements from fitting the observed absorption spectra with the modified Bidigare et al. [1990] absorption spectra model (equation (15) and Figure 7), the capability of inverting this new model estimate to the HPLC pigment observations was also assessed. For comparison, an additional inversion was carried out using equation (13), which does not contain the missing absorption term. Unfortunately, because of the way these equations are constructed it is not possible to obtain quantitative estimates due to the self-scaling nature of the pigment package effect term, any changes in the estimated pigment concentrations are readily offset by a balanced change in the packing term, yielding similar results. As a consequence, without additional information on either the level of pigment package effect or the actual concentration of a key pigment, only relative pigment ratios can be retrieved. Therefore, in order to yield some quantitative assessment of using this equation the chlorophyll a concentration was set to the HPLC observations and the LMDIF algorithm was used to solve for the remaining unknown pigment concentrations. In both cases (Table 4,

Table 5. Coefficient of Determination $\left(\mathrm{r}^{2}\right)$ Levels for Retrieval of Pigment Concentrations Using Randomly Split Data Set of All the Absorption Spectra and HPLC Observations ${ }^{\mathrm{a}}$

\begin{tabular}{|c|c|c|c|c|c|c|c|c|c|c|c|c|}
\hline \multirow{2}{*}{$\begin{array}{l}\text { Pigment } \\
\text { Name }\end{array}$} & \multicolumn{5}{|c|}{ Raw } & \multicolumn{2}{|c|}{ Auto-Normalized $^{\mathrm{b}}$} & \multicolumn{5}{|c|}{ Normalized to $675 \mathrm{~nm}$} \\
\hline & SVD & SVD-NNLS & NNLS & MRQMIN & LMDIF & Bricaud & Bricaud + Missing & SVD & SVD-NNLS & NNLS & MRQMIN & LMDIF \\
\hline chlorophyll c $(\mathrm{c} 1+\mathrm{c} 2+\mathrm{c} 2)$ & 0.01 & 0.00 & 0.00 & 0.00 & 0.01 & 0.17 & & 0.10 & 0.23 & 0.05 & 0.15 & 0.06 \\
\hline chlorophyllide & 0.03 & 0.12 & 0.03 & 0.00 & 0.04 & (b) & (b) & 0.02 & 0.26 & 0.06 & 0.10 & 0.09 \\
\hline pheophoribide & 0.02 & 0.02 & 0.03 & 0.02 & 0.02 & (b) & (b) & 0.01 & 0.06 & 0.09 & 0.14 & 0.15 \\
\hline peridinin & 0.06 & 0.16 & 0.08 & 0.16 & 0.16 & 0.54 & & 0.03 & 0.32 & 0.22 & 0.26 & 0.28 \\
\hline $19^{\prime}$ butanoy-loxyfucoxanthin & 0.01 & 0.00 & 0.01 & 0.01 & 0.02 & 0.00 & & 0.00 & 0.01 & 0.07 & 0.00 & 0.03 \\
\hline fucoxanthin & 0.15 & 0.18 & 0.14 & 0.29 & 0.33 & 0.89 & & 0.31 & 0.70 & 0.49 & 0.66 & 0.66 \\
\hline neoxanthin & 0.01 & 0.16 & 0.05 & 0.27 & 0.10 & (b) & (b) & 0.00 & 0.06 & 0.01 & 0.03 & 0.04 \\
\hline violaxanthin & 0.16 & 0.30 & 0.00 & 0.55 & 0.03 & (b) & (b) & 0.07 & 0.30 & 0.43 & 0.50 & 0.25 \\
\hline $19^{\prime}$ hexanoy-loxyfucoxanthin & 0.00 & 0.10 & 0.07 & 0.07 & 0.04 & 0.00 & & 0.04 & 0.16 & 0.04 & 0.15 & 0.06 \\
\hline diadinoxanthin & 0.04 & 0.07 & 0.00 & 0.15 & 0.08 & 0.35 & & 0.00 & 0.43 & 0.31 & 0.58 & 0.42 \\
\hline alloxanthin & 0.24 & 0.46 & 0.53 & 0.44 & 0.39 & 0.18 & & 0.25 & 0.52 & 0.34 & 0.52 & 0.57 \\
\hline diatoxanthin & 0.30 & $\mathbf{0 . 5 3}$ & 0.01 & 0.00 & 0.41 & (b) & (b) & 0.08 & 0.33 & 0.08 & 0.03 & 0.17 \\
\hline zeaxanthin & 0.39 & 0.63 & 0.44 & 0.72 & 0.65 & 0.37 & & 0.22 & 0.56 & 0.76 & 0.77 & 0.71 \\
\hline lutein & 0.01 & 0.11 & 0.22 & 0.26 & 0.19 & (b) & (b) & 0.00 & 0.03 & 0.07 & 0.09 & 0.09 \\
\hline chlorophyll $\mathrm{b}^{\mathrm{c}}$ & 0.03 & 0.39 & 0.39 & 0.60 & 0.30 & 0.24 & & 0.09 & 0.50 & 0.22 & 0.54 & 0.34 \\
\hline chlorophyll $\mathrm{a}^{\mathrm{c}}$ & 0.22 & 0.21 & 0.44 & 0.50 & 0.52 & $\mathrm{NA}^{\mathrm{d}}$ & $\mathrm{NA}^{\mathrm{d}}$ & 0.81 & 1.00 & 0.993 & 0.998 & 0.997 \\
\hline phaeophytin a & 0.26 & 0.31 & 0.22 & 0.20 & 0.15 & (b) & (b) & 0.04 & 0.16 & 0.13 & 0.14 & 0.15 \\
\hline carotenoid & 0.02 & 0.08 & 0.02 & 0.05 & 0.06 & 0.09 & & 0.23 & 0.33 & 0.39 & 0.49 & 0.46 \\
\hline
\end{tabular}

\footnotetext{
${ }^{\mathrm{a}}$ Values greater than 0.5 are in bold.

${ }^{b}$ Entries with (b) indicate pigment not included in inversion due to lack of pigment-specific absorption coefficients.

${ }^{\mathrm{c}}$ Includes both mono and divinyl.

${ }^{\mathrm{d}}$ Inversion solutions normalized against chlorophyll a values, making correlations irrelevant.
} 
Auto-Normalized cases), the ability to estimate the measured HPLC pigments was worse than what was encountered in all of the model inversions that used results from the simple matrix inversions to obtain pigment-specific absorption spectra or more appropriately "absorption modes."

[37] Global Pigment Estimates: Compared to the U.S. east coast pigment estimates, using a more globally distributed data set yielded coefficients of determination $\left(r^{2}\right)$ that were significantly lower (Table 5). Carotenoid estimates showed the most significant drop in performance. Chlorophylls a and b, zeazanthin, alloxanthin, violaxanthin, and focuxanthin had reasonable $(>0.5)$ estimations but did not perform consistently among the various inverse models. Chlorophyll a predictions were again very strong $(>.8)$ in the inverse model solutions that used the normalized absorption spectra as the inputs to the inverse models.

\section{Discussion}

[38] Developing models that link phytoplankton pigments to the IOPs of phytoplankton absorption spectra is an essential step for advancing the capabilities of hyperspectral inverse models for ocean remote sensing reflectance observations. The inversions above show that it is possible to extract pigment-specific absorption 'modes,' that can be used with measured pigment concentrations to reconstruct observed phytoplankton absorption spectra. Unlike the presently available laboratory derived pigment-specific absorption spectra [Bidigare et al., 1990; Bricaud et al., 2004], which are limited in spectral range between 400 to $700 \mathrm{~nm}$, the ESD technique is able to derive absorption relationships/modes well into to ultraviolet (UV) region of the spectrum. However, the coefficients of determination $\left(\mathrm{r}^{2}\right)$ for this spectral region $(300-400 \mathrm{~nm})$ is much less (ranging from about 0.5 to 0.92 , not shown) than for the visible region of the spectrum (Figure 7). The reason for this decrease is likely due to the fact that the pigments that were used in the inversion process did not contain the key pigments that absorb strongly in the UV region, such as mycosporine-like amino acids (MAAs) [Moisan et al., 2010].

[39] Reconstructing Phytoplankton Absorption Spectra. The differences between the ESD reconstructions and the Bricaud et al. [2004] reconstruction that was modified to include a power function to resolve the likely missing absorption term (equation (15)) presents some puzzling observations. The first of these is related to whether the pigment package effect was adequately estimated by the inclusion of a 'normalization' term in equation (15). The previous work of Bricaud et al. [2004] argues for a missing absorption component. This missing absorption component was also observed in phytoplankton absorption spectra collected at the depth of the 1\% light level off the coast of California [Nelson et al., 1993]. Certainly the lack of: a) a complete set of pigment-specific absorption spectra (only 14 versus the 18 measured HPLC pigments); b) MAA measurements; and, c) pigment concentrations and absorption spectra for the water soluble phycobiliprotiens (phycocyanin and phycoerythrin), which are absent from HPLC measurements, contributed to lowering the capabilities of all spectral reconstruction techniques. MAAs primarily absorb in the UV region, phycocyanin has peak absorption in the
608-620 nm region [Glazer et al., 1973; Debreczeny et al., 1993] and phycoerythrin absorbs primarily in the 550 to $650 \mathrm{~nm}$ region [Bryant, 1982; Ong et al., 1984]. Those spectral regions yielded lower $\mathrm{r}^{2}$ values for all absorption spectra reconstructions. The missing absorption component might result from the presence of intracellular absorbing materials that are not HPLC measured pigments and the incomplete removal of the 'detrital' absorption components, which generally have featureless absorption spectra increasing to shorter wavelengths. Results from Bidigare et al. [1989] noted that these 'non-photosynthetic chromophores' affected quantum yield measurements that relied on phytoplankton absorption spectra reconstruction techniques. The measured spectra might also be influenced by a spectrally varying pigment package effect that would alter the overall shape of the entire spectrum, thereby altering the shape and magnitude of the 'missing' absorption component. In addition to those issues mentioned above, there are also errors associated with the actual absorption spectra measurements [Mitchell et al., 2000], HPLC measurements [Bidigare et al., 2005] and pigment extraction efficiencies.

[40] A comparison (not shown) of all of the power functions against the difference between the Bricaud et al. [2004] reconstructions and the observed absorption spectra (e.g., Figure 6) shows that while the power function does a fairly decent job at modeling the overall shape of the differences, the spectral absorption in the region between 450 to $500 \mathrm{~nm}$ was consistently underestimated and overestimated in the region between 600 to $625 \mathrm{~nm}$. This consistent bias shows up in the linear regressions between the measured and reconstructed phytoplankton absorption spectra (Figure 7a). This suggests again that other pigments and their absorption spectra need to be included in the reconstructions or that the observed absorption spectra shapes are being modified by the spectral variability of the pigment package effect. The difference spectra in the Bricaud et al. [2004] reconstructions demonstrated carotenoid-like spectral signatures, which support our overall analysis. A power function fitting such spectrum would underestimate the absorption in the region from 450 to $500 \mathrm{~nm}$.

[41] It is interesting to note also that the inversion reconstructions within the UV region (300 to $400 \mathrm{~nm}$, not shown) are actually fairly well represented, even though no information is available about MAA concentrations or their absorption spectra. Some of this is likely due to the fact that MAAs have been shown to be correlated to levels of the pigment diatoxanthin [Moisan et al., 2010], which is represented in the HPLC data set. It is likely that these various levels of co-variability between the pigment concentrations, either observed (Figure 4a) or not (as in the MAAs), play a significant role in determining the final pigment-specific absorption spectra.

[42] A noticeable decline in performance of all absorption spectra reconstructions occurred in the spectral region between 550 and $650 \mathrm{~nm}$. This is likely caused by not including the contributions of phycobilin pigments to the phytoplankton absorption spectra reconstructions. Phycobilins were not included in this study because they are not part of the standard pigment suite measured in HPLC analysis. Finally, there is a consistent drop in $\mathrm{r}^{2}$ near $700 \mathrm{~nm}$ for all spectral reconstruction methods attempted in this study. Certainly in this region the absorption levels are very low 
compared to most other parts of the absorption spectra, which can enhance errors.

[43] Pigment Package Effect. The pigment package effect spectra have traditionally been calculated by dividing observed phytoplankton absorption spectra by the reconstructed absorption spectra [Nelson et al., 1993; Bricaud et al., 2004]. This is not possible for samples that demonstrate higher values of absorption that the reconstructed absorption spectra would suggest, yielding pigment package effects with values higher than 1 , values outside the defined $0-1$ range. Our results suggest that the missing absorption components should be part of the reconstructed absorption spectra equation. In doing so, the spectral shape of the pigment package effect (Figure 12) for all of the samples shows modest variability across the spectrum but a wide variability between the samples. In the grossest sense, reduced (higher value) levels of pigment package effect occurred around 480 and $680 \mathrm{~nm}$, with higher levels near the $580 \mathrm{~nm}$ region of the spectrum. This variability points back to the issue of not completely reconstructing the absorption spectra due to the variety of reasons listed previously. The manner in which the pigment package spectra are calculated (equation (18)) also causes the spectra to contain the measure of all of the errors from the absorption spectra reconstructions, making it much more difficult to believe the result. Geider and Osborne [1987] used an alternate method for estimating the magnitude of the pigment package effect that entailed comparing the ratio of intact to disrupted cell absorption. Their results showed a range in values from 0.5 at the $435 \mathrm{~nm}, 1.0$ at $600 \mathrm{~nm}$, and 0.7 at $670 \mathrm{~nm}$, which is markedly different from the general spectral variations observed in this study. Other examples of the pigment package effect estimated by the ratio of intact to disrupted cell absorption show a wide range of spectral variability [Osborne and Geider, 1989; Kirk, 1994]. One interesting example of a comparison between the absorption spectra of intact versus disrupted cells of a Synechococcus sp. (WH7803 clone) shows that the spectral shape of the pigment package effect be similar is shape to that of the 'missing absorption' term placed into the absorption model in equation (18) [see Osborne and Geider, 1989, Figure 2A]. In the methodology that is used in this paper, an assumption is made in order to obtain estimates of the pigment package effect. The assumption is that difference between the 'unpackaged' spectra and the standard Bricaud et al. [2004] reconstruction was characteristic of the absorption due to a missing absorption component that could be modeled fairly well using a power function that, oddly enough, is similar to a scattering function. However, given that MAA, phycocyanin and phycoerythrin absorption components were not included in the spectral reconstruction, and there have been a number of arguments for missing absorption [Nelson et al., 1993; Bricaud et al. 2004] and scattering [Osborne and Geider, 1989] components, much work on this issue remains. Is this 'missing absorption term' noted previously by Bricaud et al. [2004] and observed again in the results above due to absorption, some component of the pigment package effect, scattering, or a combination of them all? And, the issue of errors within the pigment absorption reconstructions have a direct impact on the spectral variability of the pigment package effect.
[44] Estimating Phytoplankton Pigments using Absorption Spectra. The ability to reconstruct laboratory-measured phytoplankton in vivo absorption spectra has been considerably improved, with the results of the present work demonstrating coefficients of determination across the visible spectrum at greater than 0.9 for several of the inversion techniques employed. The solutions obtained by reconfiguring the equations to invert across the spectrum of a single sample to obtain pigment estimates are less successful. Of the 12 inverse model solutions carried out to estimate pigment concentrations from phytoplankton absorption spectra, none had all good $\left(\mathrm{r}^{2}>0.6\right)$ retrievals, for either the U.S. east coast or global ocean data sets. The best performer using the more regional U.S. east coast observations is from using the SVD-NNLS method, which uses the SVD algorithm to obtain pigment-specific absorption spectra and then the NNLS algorithm to solve for the pigments using the observed phytoplankton absorption spectra. The results are significantly improved for most of the inversions if the absorption spectra are first 'normalized' to the expected $675 \mathrm{~nm}$ absorption levels.

[45] Most pigments show either consistently good (chlorophyll a, chlorophyll c, peridinin, fucoxanthin, diadinoxanthin, and carotenoids) or poor (chlorophyllide, both fucoxanthin, diatoxanthin, zeaxanthin, and lutein) retrievals. There are a number of factors that are likely contributors to this. The first is related to the ESD approach that is used to generate pigment-specific absorption. A number of the pigments are correlated (Figure 4), adding complexity to the inversion solutions. In addition, the solutions explicitly contain the influence of the pigment package effect. Both of these add more degrees of freedom to an already overly complex set of observations. Also, the spectral inversions are done at a spectral resolution of $1 \mathrm{~nm}$, which is of the order of spectral distance between several absorption spectra (Figure 1). Results from twin experiments to test the development of these inversion techniques (not shown) show that inverse model solutions are sensitive to the spectral resolution used and the level of errors in the measured phytoplankton absorption spectra.

\section{Conclusions}

[46] Phytoplankton absorption spectra and pigment observations can be used with an inverse modeling technique to support a second inversion method that estimates phytoplankton pigment concentrations directly from phytoplankton absorption spectra. This capability can be directly inserted in present hyperspectral remote sensing inverse models to expand the pigment products being recovered. The lack of measurements of MAA's, phycobiliproteins and other pigments impacts the capability of this technique to retrieve pigment-specific absorption spectra and estimates of pigment concentrations. In addition, the pigment estimations are less accurate for those pigments whose combined absorption levels and concentrations have a low influence on the final total absorption spectra. Finally, the most accurate model for estimation of phytoplankton total absorption, which possibly accounts for pigment package effect and a missing absorption term, is less able to be inverted to estimate phytoplankton pigments that the more robust and straightforward ESD 
method that calculated pigment-specific absorption 'modes.' The SVD inversion is the most robust for inversion applications, even with its problem in not being able to guarantee nonnegative absorption or pigment values. The inversions show good retrievals for a number of phytoplankton pigments from water samples obtained within a region of the U.S. East Coast. The capability to obtain pigment retrievals is lower when using a larger global ocean data set. It is likely that this method can only be best applied in a regional setting.

[47] Acknowledgments. We thank Kristin Golmon for earlier validation, testing and development of a MATLAB version of the inversion algorithm using MATLAB software through the support of the NASA USRP Student Program. We thank Kristen Blattner and Carla P. Makinen for processing of some of the absorption data. We thank Frank Hoge and Paul Lyon for their careful reading and insightful comments. We also would like to acknowledge the two reviewers of the manuscript whose constructive criticisms have made this a much more robust study. Our HPLC data sets (BIOME, COBY, and MAA cruises) were processed by Laurie van Heukelum (UMCES, Univ. of MD, Horn Point). Our work is partially funded by the Biodiversity Program (TAM) at NASA and internal NASA funds. Special acknowledgments are made to those who have contributed their valuable data sets on phytoplankton absorption and HPLC pigment observations to the NASA SeaBASS data archive, and to those who have maintained the SeaBASS archive, specifically Jeremy Werdell (NASA/GSFC). Noteworthy contributors to the observations used in this study include: Norman Nelson and David Siegel (UC Santa Barbara), Lawrence Harding (UMCES, University of Maryland, Horn Point), Richard Zimmerman and the late Glenn Cota (ODU), Adjit Subramaniam (LDGO), Heidi Sosik (WHOI) and Heidi Dierssen (University of Connecticut)

\section{References}

Behrenfeld, M. J., and P. G. Falkowski (1997), A consumer's guide for phytoplankton primary productivity, Limnol. Oceanogr., 42(7), 1479-1491, doi:10.4319/lo.1997.42.7.1479.

Bidigare, R. R., O. Schofield, and B. B. Prézelin (1989), Influence of zeaxanthin on quantum yield of photosynthesis of Synechococcus clone WH7803(DC2), Mar. Ecol. Prog. Ser., 56, 177-188, doi:10.3354/ meps056177.

Bidigare, R. R., M. E. Ondrusek, J. H. Morrow, and D. A. Kiefer (1990), In vivo absorption properties of algal pigments, Proc. SPIE, 1302, 290-302.

Bidigare, R. R., L. Van Heukelem, and C. C. Trees (2005), Analysis of algal pigments by high-performance liquid chromatography, in Algal Culturing Techniques, edited by R. Anderson, pp. 327-345, Academic, Burlington, Mass.

Bricaud, A., H. Claustre, J. Ras, and K. Oubelkheir (2004), Natural variability of phytoplankton absorption in oceanic waters: Influence of the size structure of algal populations, J. Geophys. Res., 109, C11010, doi:10.1029/2004JC002419.

Bryant, D. A. (1982), Phycocyanin and phycoerythrin: Properties and occurrence in cyanobateria, J. Gen. Microbiol., 128, 835-844.

Carr, M.-E., et al. (2006), A comparison of global estimates of marine primary production from ocean color, Deep Sea Res., Part II, 53, 741-770, doi:10.1016/j.dsr2.2006.01.028

Ciotti, A. M., M. R. Lewis, and J. J. Cullen (2002), Assessment of the relationships between dominant cell size and natural phytoplankton communities and the spectral shape of the absorption coefficient, Limnol. Oceanogr., 47, 404-417, doi:10.4319/lo.2002.47.2.0404.

Debreczeny, M. P., K. Sauer, J. Zhou, and D. A. Bryant (1993), Monomeric C-phycocyanin at room temperature and $77 \mathrm{~K}$ : Resolution of the absorption and fluorescence spectra of the individual chromophores and the energy-transfer rate constants, J. Phys. Chem., 97, 9852-9862, doi:10.1021/j100140a 050 .

Evans, D. J., and D. Cornford (2003), Bayesian pigment retrieval, paper presented at Practical Bayesian Statistics 5, Open Univ., Milton Keynes, U. K.

Geider, R. J., and B. A. Osborne (1987), Light absorption by a marine diatom: Experimental observations and theoretical calculations of the package effect in a small Thallassiosira species, Mar. Biol., 96, 299-308, doi:10.1007/BF00427030.

Glazer, A. N., S. Fang, and D. M. Brown (1973), Spectroscopic properties of C-phycocyanin and of its $\alpha$ and $\beta$ subunits, J. Biol. Chem., $248,5679-5685$.
Hiebert, K. L. (1980), A comparison of software which solves systems of nonlinear equations, Rep. SAND 80-0181, Sandia Lab., Albuquerque, N. M.

Hoepffner, N., and S. Sathyendranath (1991), Effect of pigment composition on absorption properties of phytoplankton, Mar. Ecol. Prog. Ser., 73, 11-23, doi:10.3354/meps073011.

Hoge, F. E., and P. E. Lyon (1996), Satellite retrieval of inherent optical properties by linear matrix inversion of oceanic radiance models: An analysis of model and radiance measurements, J. Geophys. Res., 101, 16,631-16,648, doi:10.1029/96JC01414

Hoge, F. E., and P. E. Lyon (1999), Spectral parameters of inherent optical property models: Methods for satellite retrieval by matrix inversion of an oceanic radiance model, Appl. Opt., 38, 1657-1662, doi:10.1364/ AO.38.001657.

International Ocean-Colour Coordinating Group (IOCCG) (2006), Remote Sensing of Inherent Optical Properties: Fundamentals, tests of algorithms, and applications, in Reports of the International Ocean-Colour Coordinating Group, IOCCG Rep. 5, edited by Z.-P. Lee, Dartmouth, N.S., Canada.

Kirk, J. T. O. (1994), Light and Photosynthesis in Aquatic Ecosystem, 2nd ed., Cambridge Univ. Press, Cambridge, U. K., doi:10.1017/ CBO9780511623370

Kishino, M., N. Okami, M. Takahashi, and S. Ichimura (1985), Estimation of the spectral absorption coefficients of phytoplankton in the sea, Bull. Mar. Sci., 37, 634-642.

Lawson, C. L., and R. J. Hanson (1974), Solving Least Square Problems, Prentice Hall, Englewood Cliffs, N. J.

Levenberg, K. (1944), A method for the solution of certain problems in least squares, Q. Appl. Math., 2, 164-168.

Lohrenz, S. E., A. D. Weidemann, and M. Tuel (2003), Phytoplankton spectral absorption as influenced by community size structure and pigment composition, J. Plankton Res., 25, 35-61, doi:10.1093/plankt/25.1.35.

Lutz, V. A., S. Sathyendranath, and E. J. H. Head (1996), Absorption coefficient of phytoplankton: Regional variations in the North Atlantic, Mar. Ecol. Prog. Ser., 135, 197-213, doi:10.3354/meps135197.

Mackey, M. D., D. J. Mackey, H. W. Higgins, and S. W. Wright (1996), CHEMTAX - A program for estimating class abundances for chemical markers: An applications to HPLC measurements of phytoplankton, Mar. Ecol. Prog. Ser., 144, 265-283, doi:10.3354/meps144265.

Maritorena, S., D. A. Siegel, and A. R. Peterson (2002), Optimization of a semianalytical ocean color model for global-scale applications, Appl. Opt., 41(15), 2705-2714.

Marquardt, D. (1963), An algorithm for least-squares estimation of nonlinear parameters, SIAM J. Appl. Math., 11, 431-441, doi:10.1137/0111030.

Mitchell, B. G. (1990), Algorithms for determining the absorption coefficient of aquatic particulates using the quantitative filter technique (QFT), Proc. SPIE, 1302, 137-148.

Mitchell, B. G., et al. (2000), Determination of spectral absorption coefficients of particles, dissolved organic material and phytoplankton for discrete water samples, in Ocean Optics Protocols for Satellite Ocean Color Sensor Validation Revision 2, NASA Tech. Memo. 2000-209966, edited by G. S. Fargion and J. L. Mueller, chap. 12, NASA Goddard Space Flight Cent., Greenbelt, Md.

Moisan, T. A., and B. G. Mitchell (1999), Photophysiological acclimation of Phaeocystis Antarctic Karsten under light limitation, Limnol. Oceanogr., 44, 247-258, doi:10.4319/lo.1999.44.2.0247.

Moisan, T. A., J. Goes, and P. J. Neale (2010), Mycosporine-like amino acids in phytoplankton: Biochemistry, physiology, and optics, in Marine Phytoplankton, edited by W. T. Kersey and S. P. Munger, chap. 4, Nova Sci., New York.

Morel, A., and A. Bricaud (1981), Theoretical results concerning light absorption in a discrete medium, and application to specific absorption of phytoplankton, Deep Sea Res., Part A, 28, 1375-1393.

Nelson, N. B., B. B. Prezlin, and R. R. Bidigare (1993), Phytoplankton light absorption and the package effect in California coastal waters, Mar. Ecol. Prog. Ser., 94, 217-227, doi:10.3354/meps094217.

Ong, L. J., A. N. Glazer, and J. B. Waterbury (1984), An unusual phycoerythrin from a marine cyanobacterium, Science, 224, 80-83, doi:10.1126 science. 224.4644 .80

Osborne, B. A., and R. J. Geider (1989), Problems in the assessment of the package effect of five small phytoplankters, Mar. Biol. Berlin, 100, 151-159, doi:10.1007/BF00391954.

Press, W. H., S. A. Teukolsky, W. T. Vetterling, and B. P. Flannery (2007), Numerical Recipes: The Art of Scientific Computing, Cambridge Univ. Press, Cambridge, U. K.

Stuart, V., S. Sathyendranath, T. Platt, H. Maass, and B. D. Irwin (1998), Pigments and species composition of natural phytoplankton populations: Effect on the absorption spectra, J. Plankton Res., 20, 187-217, doi:10.1093/plankt/20.2.187. 
Vallino, J. J. (2000), Improving marine ecosystem models: Use of data assimilation and mesocosm experiments, J. Mar. Res., 58, 117-164, doi: $10.1357 / 002224000321511223$.

Van Heukelem, L., and C. S. Thomas (2001), Computer-assisted highperformance liquid chromatography method development with applications to the isolation and analysis of phytoplankton pigments, J. Chrom. A., 910, 31-49, doi:10.1016/S0378-4347(00)00603-4.

Werdell, P. J., and S. W. Bailey (2002), The SeaWiFS Bio-optical Archive and Storage System (SeaBASS): Current architecture and implementation, edited by G. S. Fargion and C. R. McClain, NASA Tech. Memo. 2002-211617, 45 pp., NASA Goddard Space Flight Cent., Greenbelt, Md. Werdell, P. J., S. W. Bailey, G. S. Fargion, C. Pietras, K. D. Knobelspiesse, G. C. Feldman, and C. R. McClain (2003), Unique data repository facil- itates ocean color satellite validation, Eos Trans. $A G U, 84(38), 377$, doi:10.1029/2003EO380001.

J. R. Moisan and T. A. H. Moisan, Hydrospheric and Biospheric Sciences Laboratory, Wallops Flight Facility, NASA Goddard Space Flight Center, Bldg. N159, Rm. E217, Wallops Island, VA 23337, USA. (john.r.moisan@nasa.gov)

M. A. Linkswiler, URS Corporation, Wallops Flight Facility, NASA Goddard Space Flight Center, Bldg. N159, Rm. E203, Wallops Island, VA 23337, USA. 